\title{
The awr Gene Family Encodes a Novel Class of Ralstonia solanacearum Type III Effectors Displaying Virulence and Avirulence Activities
}

\author{
Montserrat Solé, ${ }^{1}$ Crina Popa, ${ }^{1}$ Oriane Mith, ${ }^{1}$ Kee Hoon Sohn, ${ }^{2}$ Jonathan D. G. Jones, ${ }^{2}$ \\ Laurent Deslandes, ${ }^{3}$ and Marc Valls ${ }^{1}$ \\ ${ }^{1}$ Dept. Genètica, Universitat de Barcelona, Av. Diagonal 643 Annex, 08028 Barcelona, and Centre de Recerca Agrigenòmica, \\ Edifici CRAG, Campus UAB, 08193 Bellaterra, Catalonia, Spain; ${ }^{2}$ The Sainsbury Laboratory, John Innes Centre, Norwich \\ Research Park, Norwich NR4 7UH, U.K.; ${ }^{3}$ Laboratoire des Interactions Plantes Micro-organismes, UMR CNRS-INRA \\ 2594/441, 31320 Castanet Tolosan, France
}

Submitted 23 December 2011. Accepted 4 March 2012.

\begin{abstract}
We present here the characterization of a new gene family, $a w r$, found in all sequenced Ralstonia solanacearum strains and in other bacterial pathogens. We demonstrate that the five paralogues in strain GMI1000 encode type III-secreted effectors and that deletion of all $a w r$ genes severely impairs its capacity to multiply in natural host plants. Complementation studies show that the AWR (alanine-tryptophanarginine tryad) effectors display some functional redundancy, although AWR2 is the major contributor to virulence. In contrast, the strain devoid of all $a w r$ genes ( $\Delta a w r$ 1-5) exhibits enhanced pathogenicity on Arabidopsis plants. A gain-of-function approach expressing AWR in Pseudomonas syringae pv. tomato $\mathrm{DC} 3000$ proves that this is likely due to effector recognition, because AWR5 and AWR4 restrict growth of this bacterium in Arabidopsis. Transient overexpression of AWR in nonhost tobacco species caused macroscopic cell death to varying extents, which, in the case of AWR5, shows characteristics of a typical hypersensitive response. Our work demonstrates that AWR, which show no similarity to any protein with known function, can specify either virulence or avirulence in the interaction of $R$. solanacearum with its plant hosts.
\end{abstract}

Bacterial pathogens have been extraordinarily useful to characterize the mechanisms of virulence and plant defense. Plant infection and colonization by bacterial pathogens often requires the injection of so-called effector proteins into host cells through the type III secretion system (T3SS) (Buttner and He 2009; Galan and Collmer 1999; Marlovits and Stebbins 2009). This molecular syringe is present in gram-negative bacterial pathogens or mutualists that interact with animals or plants (He et al. 2004; Preston 2007). In phytopathogenic bacteria, a cluster of 20 to 25 hypersensitive response (HR) and pathogenicity ( $h r p$ ) genes encodes the T3SS that is essential for virulence because T3SS-deficient mutants cannot elicit HR or cause dis-

Corresponding author: M. Valls; Telephone: +34 93 4021499; Fax: +34 93 4034420; E-mail: marcvalls@ub.edu

* The $e$-Xtra logo stands for "electronic extra" and indicates that three supplementary tables and three supplementary figures are published online.

This article is in the public domain and not copyrightable. It may be freely reprinted with customary crediting of the source. The American Phytopathological Society, 2012. ease on resistant or susceptible plants, respectively (Alfano and Collmer 2004).

Bacterial effectors contribute to the establishment or development of disease (Hogenhout et al. 2009; Lewis et al. 2009), although the mechanisms by which effectors function inside plant cells are not fully understood. Type III-secreted effectors (T3E) from phytopathogens of the genera Pseudomonas and Xanthomonas have been widely studied and shown to interfere with plant signal transduction by acting as proteases, phosphatases, ubiquitin ligases, ribosyltransferases, and phosphothreonine lyases (Dean 2011; Hann et al. 2010; Zhou and Chai 2008).

During coevolution with microbes, plants have developed innate immune mechanisms to counterattack invading pathogens (Cui et al. 2009; Jones and Dangl 2006). Two main layers of defense responses have been described: pathogen-associated molecular pattern (PAMP)-triggered immunity (PTI) and effector-triggered immunity (ETI). PTI consists of a general resistance directed toward invading microbes and is activated upon detection of PAMP molecules via pattern recognition receptors (Segonzac and Zipfel 2011). ETI represents a stronger version of this defense. ETI usually culminates in the elicitation of the plant HR, a localized programmed cell death associated with strong race- or cultivar-specific resistance (Coll et al. 2011; Tsuda and Katagiri 2010). One of the main roles of effectors is the suppression or modulation of PTI or ETI (Block et al. 2008; Lewis et al. 2009; Stavrinides et al. 2008). The amplitude of disease resistance or susceptibility for a specific plantpathogen interaction thus depends on four variables: i) the PTI plant response, ii) the interference of PTI by bacterial effectors, iii) the ETI, and iv) the capacity of some effectors to suppress ETI (Jones and Dangl 2006). Heterologous expression of bacterial T3E in different pathosystems and characterization of the resulting phenotype can provide important clues to both their function and plant defense mechanisms.

Ralstonia solanacearum is the causal agent of bacterial wilt on more than 200 plant species from 50 botanical families, including economically important crops such as potato, tomato, tobacco, banana, and eggplant (Boucher et al. 1987; Hayward 2000). The bacterium has a strong impact in tropical and subtropical agriculture because of its unusually wide host range, its high persistence and aggressiveness, and the lack of resistant crop varieties (Hong et al. 2005). The sequencing of $R$. solanacearum GMI1000 (Salanoubat et al. 2002) led to the identification of 70 putative T3E (Mukaihara et al. 2010; 
Poueymiro et al. 2009). The only two $R$. solanacearum effectors that have been attributed a biochemical function thus far are the GALA effectors, which mimic plant E3 ubiquitin ligases (Angot et al. 2006) and the YopJ-like protein PopP2, which functions as acetyltransferase (Tasset et al. 2010). PopP2 was pinpointed as the GMI1000 avirulence (Avr) protein recognized by the RRS1-R resistance (R) protein of the Arabidopsis thaliana resistant accession Nd-1 (Deslandes et al. 2003). In addition, AvrA and PopP1 effectors are also known to trigger plant defense responses. AvrA was shown to be an avirulence determinant of various $R$. solanacearum strains in Nicotiana tabacum (Carney and Denny 1990; Robertson et al. 2004) and recent reports have also suggested a role in pathogenicity (Macho et al. 2010; Turner et al. 2009). PopP1 was described as a host-specificity factor that behaves as a typical avirulence gene in Petunia spp. (Lavie et al. 2002) and that plays a minor contribution to the HR in tobacco plants (Poueymiro et al. 2009).

Among the T3E candidates in $R$. solanacearum, there is a multigenic family called AWR for the alanine-tryptophan-arginine tryad found in a highly conserved region in their primary sequence. AWR are long polypeptides of 1,063 to 1,330 amino acids. Strain GMI1000 contains five awr genes (Rsc2139, Rsp0099, Rsp0846, Rsp0847, and Rsp1024) that we have called here $a w r 1, a w r 2$, awr3, awr4, and $a w r 5$, respectively. Except for $a w r l$, these genes are present in all $R$. solanacearum phylotypes (Guidot et al. 2007) and their transcriptional activation requires $\mathrm{HrpB}$, a master regulator of the T3SS (Cunnac et al. 2004a). AWR2 was one of only two T3E whose disruption in GMI1000 showed delayed disease symptom development on tomato, indicating an important role in bacterial pathogenesis (Cunnac et al. 2004a).

In this work, we sought to characterize the contribution of AWR to $R$. solanacearum interactions with plant hosts. Our data indicate that the AWR gene family collectively contributes to bacterial virulence and that some members are recognized in nonhost plants.

\section{RESULTS AND DISCUSSION}

\section{AWR: a T3E family conserved \\ in various plant and animal pathogens.}

Genomic analysis of the awr genes in $R$. solanacearum GMI1000 showed some interesting features: i) four of the $a w r$ genes ( $a w r 2$ to $a w r 5)$ are borne by the megaplasmid whereas awrl is located on the chromosome; ii) awr3 and awr4 lie side by side and adjacent to the hrp gene cluster; iii) awr2 and awr 5 are placed near alternative codon usage regions, often indicative of genes that have been acquired by lateral gene transfer (Arnold et al. 2003; Guidot et al. 2007); and iv) the chromosomal paralogue $a w r l$ encodes the only protein whose translocation was not detected in previous studies, although the gene seems functional because it has not accumulated any missense mutations. Pairwise analysis of AWR protein sequences from GMI1000 revealed that they all shared high identity and similarity (19 to $53 \%$ and 27 to $62 \%$, respectively). A survey of all available sequences in databases was performed to search for AWR orthologs. These comparisons revealed homologous genes or proteins with varying degrees of similarity in all sequenced strains of $R$. solanacearum, including phylotypes I (GMI1000, RS1000, and OE1-1), II (CFBP2957, IPO1609, Molk2, and UW551), III (CMR15), and IV (PSI07). We confirmed that genes awr2, awr3, awr4, and $a w r 5$ are present in all $R$. solanacearum strains whose genome has been entirely sequenced. AWR2, AWR3, and AWR4 are present even in $R$. syzygii, a related strain included in the $R$. solanacearum phylotype IV. This was in agreement with com- parative genomic hybridization analyses of $12 R$. solanacearum strains representative of all phylotypes, where these four AWR were considered core effector proteins, emphasizing their functional importance (Guidot et al. 2007). In contrast, AWR1 is absent from phylotypes II, III, and IV.

Significant similarities to AWR outside the $R$. solanacearum species were only detected with protein sequences and not at the DNA level. This is not unexpected because DNA sequences among distantly related species may differ considerably whereas protein regions important for the function are conserved. Related proteins were identified in other bacterial plant pathogens or symbionts such as several sequenced Xanthomonas strains, two Acidovorax avenae strains, and some Burkholderia spp. Surprisingly, AWR homologous proteins were also found in the animal pathogen Burkholderia pseudomallei (Supplementary Table S1). Interestingly enough, among AWR homologues in Xanthomonas oryzae pv. oryzae is XopZ (named secXoO here), which was recently shown to be involved in virulence and inhibition of basal defense (Song and Yang 2010). However, this protein is quite divergent from those of $R$. solanacearum and is more related to Pseudomonas syringae HopAS1, not considered in our studies because it did not appear as a BLAST result of AWR. To identify the most conserved regions, all proteins that showed a significant similarity to AWR $(e$ value $<0.01$ with a sequence coverage $\geq 30 \%$ or sequence identity $\geq 20 \%$ with higher $e$ values) were aligned using the MAFFT program (Katoh et al. 2002) and edited with GBlocks (Castresana 2000). Interestingly, pairwise similarity between AWR was comparable with that of their putative counterparts in other species. Sequence conservation extended all along the polypeptide sequence, showing some scattered highly conserved regions. A domain containing the AWR tripeptideafter which the protein family was named-was especially apparent as remarkably well-conserved not only in Ralstonia but also in Burkholderia spp. (Supplementary Fig. S1).

To better understand the relationships between different AWR, we constructed a phylogenetic tree based on sequence similarities using a Bayesian estimation of phylogenies (MrBAYES) (Fig. 1A). The tree obtained was rooted in the Xanthomonas sequences, which correspond to $\gamma$-proteobacteria, more distantly related to the rest of $\beta$-proteobacterial sequences. The tree showed that maximal diversification of AWR was found in $R$. solanacearum strains, whose five proteins appeared as distinct branches (Fig. 1A). Interestingly, AWR from different strains clustered together in orthologous groups rather than with the other paralogues from the same strain. This indicates that they correspond to ancestral effectors that emerged before $R$. solanacearum speciation. Three clades were observed among $R$. solanacearum AWR, containing the sequences of AWR 3 and 4, 1 and 2, and 5. The observations that i) AWR3 and AWR4 form twin branches in the phylogenetic tree, ii) they are placed side by side in the genome, and iii) they show the highest identity and similarity values strengthen the hypothesis that these genes emerged from a recent duplication event. Molk2 and UW551 strains harbor an extra $a w r$ gene that has been called AWR6 (Poueymiro and Genin 2009). According to our tree, these effectors (t3e2RsM and pawrRsU) correspond to a second copy of AWR5. This extra AWR5 is also present in IPO1609 strain RSIPO_01281 but not in the other phylotype II strain, CFBP 2957. The tree also clarified the phylogenetic relationships of AWR-related proteins found in other species. For instance, the AWR present in Xanthomonas spp., where the tree was rooted, is highly related to the common ancestor of the family. Similarly, the AWR found in strains of the human pathogen B. pseudomallei form a distinct ancestral clade. A. avenae pv. citruli contains two AWR: one in a basal branch close to Xanthomonas proteins 
and the other (hyp1 $\mathrm{AaC}$ and hypAaA) related to $R$. solanacearum sequences. Finally, an effector closely related to the AWR3/4 ancestor is present in plant pathogens from the Burkholderia genus (e.g., hyp1 Bg), which carry a copy of AWR1 (e.g., hyp2 Bg) as well, an effector otherwise restricted to the $R$. solanacearum phylotype I.

Based on all of these observations, we proposed an evolutionary model for AWR (Fig. 1B), in which the origin of these effectors preceded the splitting of $\beta$ - and $\gamma$-proteobacteria (Naum et al. 2009; Tayeb et al. 2008; Wu and Eisen 2008). From this origin, the gene family experienced several duplications or deletions in the $\gamma$-proteobacteria lineage. This explains the presence of an ancestor for $a w r 3$ and awr4 in several Burkholderia spp. and suggests that $a w r l$ appeared as a recent duplication of awr2. The model also includes two recent horizontal gene transfer events that took place from $R$. solanacearum toward plant pathogens or symbionts of the genera Acidovorax and Burkholderia. The well-known instability of the $R$. solanacearum genome (Guidot et al. 2009) and the fact that Burkholderia spp. and A. avenae share the same soil habitat (Attree and Attree, 2001; Ham et al. 2010; Viallard et al. 1998; Willems et al. 1992) render these gene transfers very likely. The evolutionary model results in five AWR members in each Ralstonia strain, except in UW551 and Molk5, where an extra duplication event in awr5 gave rise to awr6.
Finally, we performed BLAST comparisons of AWR protein or gene sequences with the databanks, and no similarity to characterized proteins or motifs with predicted biochemical function was found. Prediction analysis for sequence motifs was performed with INTERPRO Scan software, which analyzes different data sources using the protein sequences or consensus sequences derived from the most conserved domains. Threedimensional structure predictions using PHYRE were also performed and rendered no statistically relevant hits for any of the AWR proteins.

Thus, $a w r$ genes are conserved genes widespread in $R$. solanacearum, with orthologs present in other bacterial pathogens, but their sequence information gives no clue to their function.

\section{AWR are bona fide T3E.}

Previous studies demonstrated that $a w r$ genes, except for $a w r l$, were transcriptionally regulated by the T3SS master regulator $h r p B$ (Cunnac et al. 2004a). In addition, AWR2 from GMI1000 or the homologues of AWR3, AWR4, and AWR5 in phylotype I strain RS1000 were shown to be translocated into the plant cell using the cyaA reporter system (Cunnac et al. 2004a; Mukaihara and Tamura 2009). In order to confirm the type-III dependent secretion of the effectors from GMI1000, we took advantage of a novel tool that allows stable production

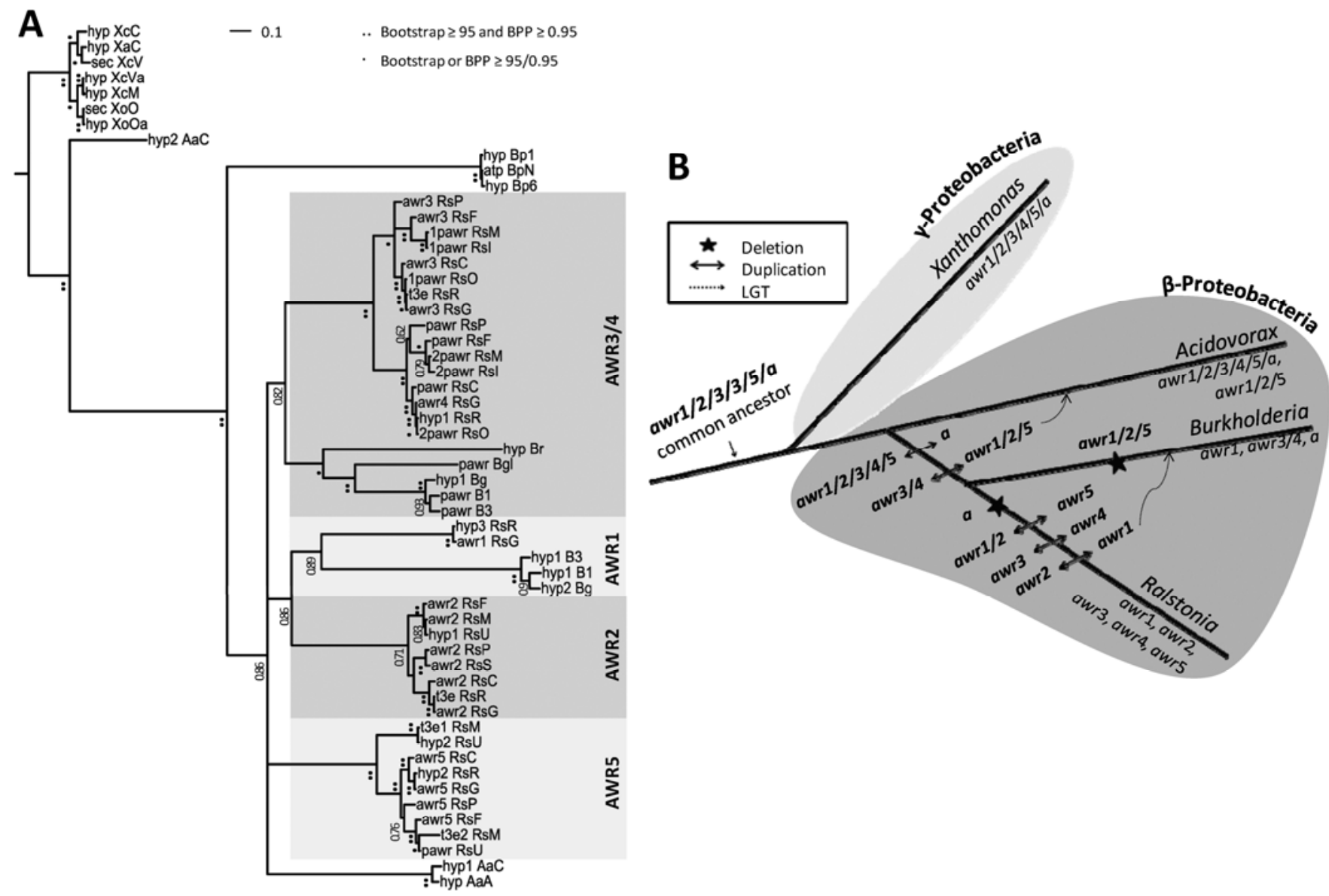

Fig. 1. Evolutionary relationships between $a w r$ genes. A, Rooted phylogenetic tree of the $a w r$ gene family. The tree was constructed, according to the Bayesian inference, from those sequences obtained by BLAST for each GMI1000 alanine-tryptophan-arginine tryad (AWR). Sequences were named after acronyms of the protein annotation in the original databanks followed the species they belonged to; that is, t3e (type 3 effector), hyp (hypothetical protein), awr (awr protein), pawr (putative awr protein), atp (atp-binding protein), sec (secreted protein), Rs (Ralstonia solanacearum), Xa (Xanthomonas axonopodis), Xc (X. campestris), Xo (X. oryzae), Aa (Acidovorax avenae), Bp (Burkholderia pseudomallei), $\mathrm{Br}$ (B. rhizoxinica), Bg (B. graminis), Bgl (B. glumae), and B (Burkholderia spp.). Numbers in branch nodes correspond to the BPP value and branch lengths indicate sequence divergence. B, Model of awr evolution in the gram-negative bacterial lineage. The model represents the most plausible evolutionary scenario, taking into account the phylogenetic relationships amongst bacteria and minimizing the number of gene duplications and losses. Xanthomonas and Acidovorax spp. contain the sequence considered more related to the ancestral form. Gene duplications are represented as arrows, deletions by stars, and putative horizontal gene transfers by discontinuous lines. 
of tagged proteins in $R$. solanacearum (Monteiro et al. 2012). We fused the hemagglutinin (HA) sequence to the $3^{\prime}$ end of the awr coding sequences under the control of the strong eps promoter and introduced the constructs in the genome of the wildtype GMI1000 strain or its T3SS-deficient counterpart $\left(h r p V^{-}\right)$ by recombination. Next, we grew the strains under type IIIinducing conditions and evaluated AWR expression inside the bacterium and their secretion to the culture medium. Thus, total bacterial protein extracts and concentrated proteins from the culture medium were obtained and subjected to immunoblot analysis using an anti-HA antibody. Distinct band sizes corresponding to the different expressed effectors could be distinguished in cell lysates of both strains (Fig. 2). Although fulllength AWR were produced in $R$. solanacearum, the protein was detected in the medium from the wild-type strain but not from the $h r p V$ mutant, thereby demonstrating that secretion was dependent on a functional T3SS. These results confirmed that AWR2, AWR3, AWR4, and AWR5 were secreted via the T3SS, as previously described using the CyA reporter assay (Cunnac et al. 2004b; Mukaihara and Tamura 2009). In addition, our data demonstrate that, contrary to what had been reported, AWR1 is also secreted to the medium and, thus, can be considered a genuine T3E protein (Fig. 2).

\section{AWR effectors jointly contribute to the pathogenicity of $R$. solanacearum GMI1000.}

A previous study showed that disruption of a single $a w r$ gene slightly affects bacterial pathogenicity. To better evaluate the combined contribution of the whole gene family in pathogenicity, we constructed a mutant of $R$. solanacearum GMI1000 devoid of all awr members. To this end, we used a recently adapted methodology for precise excision of DNA sequences in the $R$. solanacearum genome that allows the generation of cumulative mutations (Angot et al. 2006; Marx and Lidstrom 2002). Consecutive deletion of all five $a w r$ genes resulted in strain $\Delta a w r l-5$ and each of the intermediate mutants ( $\Delta a w r 3,4 ; \Delta a w r 3-5$; and $\Delta a w r 2-5)$. These mutant strains were tested for virulence in the host plants tomato (ecotypes 'Marmande' and 'Hawaii 7996') and eggplant 'Zebrina'. Bacterial multiplication was measured in the leaves, because this methodology was shown to be more sensitive and quantitative than plant disease scoring (Macho et al. 2010). The wild-type strain GMI1000 and a nonpathogenic hrp regulation mutant were used as references in this experiment. GMI1000 (wild type) multiplied 1,000 to 10,000 times at 3 days postinoculation (dpi) in infected plants, depending on the host, whereas

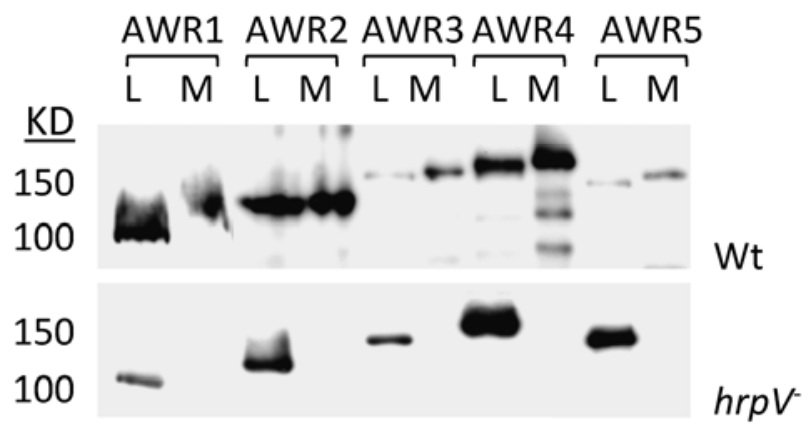

Fig. 2. Secretion assay of alanine-tryptophan-arginine tryad (AWR) effectors in Ralstonia solanacearum GMI1000. Immunodetection of protein extracts from bacterial lysates (L) or culture media of strains bearing different AWR effector genes fused to the hemagglutinin (HA) epitope tag. The wild-type GMI1000 was used to test protein secretion in the medium and the $h r p V^{-}$mutant to verify that secretion was type III secretion system specific. AWR proteins were detected with an anti-HA antibody.
hrpG multiplied a maximum of $1.5 \log _{10}$ (Fig. 3). The bacterium grew to a similar extent in the hosts tomato (Marmande) and eggplant but much less in the tomato Hawaii 7996, known to be tolerant to the disease (Wang et al. 2000). In eggplant, the multiplication capacity of the quintuple $a w r$ mutant and all its intermediates was significantly reduced compared with the wild-type strain, except for the mutant deleted for AWR3 and AWR4 $(\Delta a w r 3,4)$, whose growth was only slightly affected (Fig. 3A). The mutant devoid of all AWR multiplied 50-fold less than the wild-type strain, demonstrating an important role of AWR in pathogenicity. The whole gene family was key for bacterial progression in planta, because consecutive deletions exerted an additive effect in the phenotype. These phenotypes are specific for plant colonization, because none of the tested strains was affected in growth in culture media (data not shown). Similar results were obtained in tomato (Fig. 3B). In contrast, when the effects of single $a w r$ deletion mutations on virulence were compared, no significant differences were observed (Supplementary Fig. S2), except for AWR2, which had

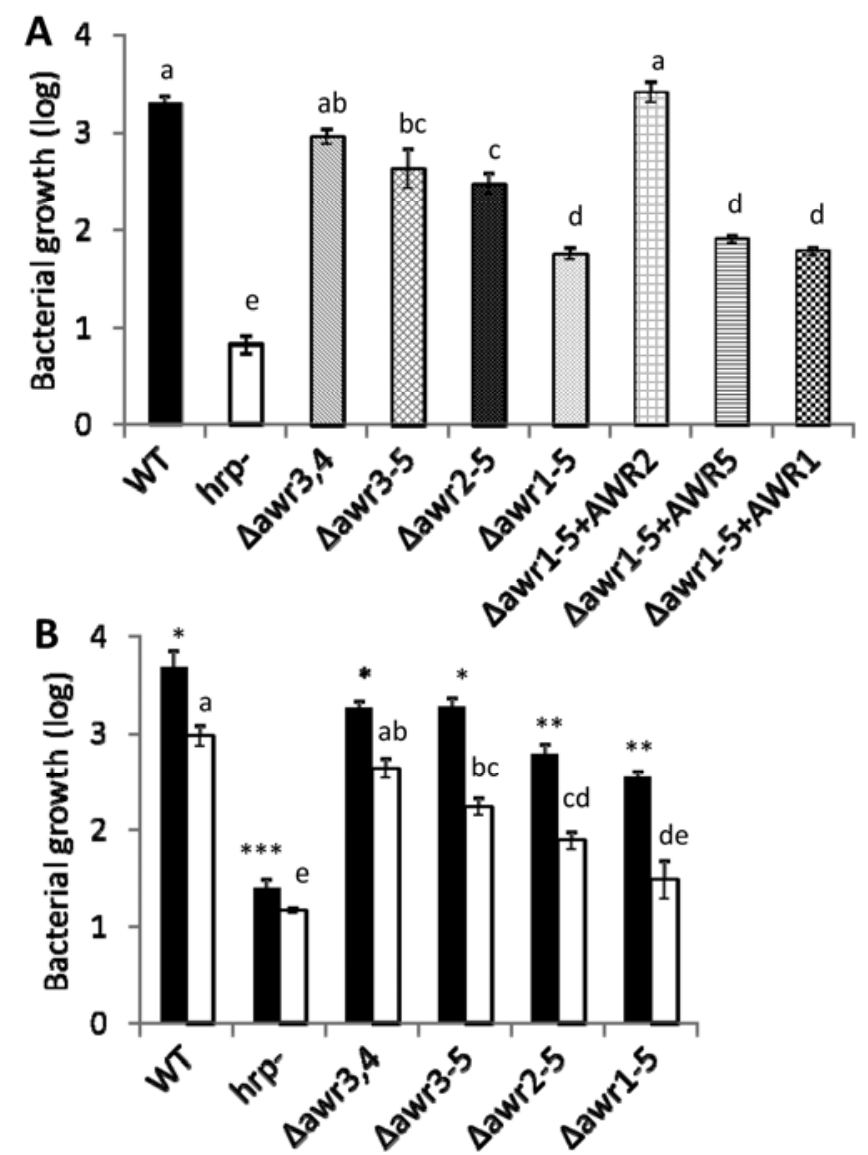

Fig. 3. Bacterial growth of alanine-tryptophan-arginine tryad (AWR) deletion mutants and their complemented strains on host plants. The wild-type Ralstonia solanacearum GMI1000 (WT), its hypersensitive response and pathogenicity $(h r p)$-deficient counterpart $\left(h r p G^{-}\right)$, and AWR mutant strains of mutant complemented strains were infiltrated at $10^{5} \mathrm{CFU} / \mathrm{ml}$ on leaves and recovered 3 days later (4 days for tomato 'Hawaii 7796') to monitor bacterial growth. Bacterial multiplication is represented as the logarithm of recovered CFU per square centimeter with respect to the original inoculum. Values represent the mean of eight biological replicates and their standard errors which were obtained in two independent assays. Statistically significant groups (letters and asterisks) were calculated using a one-way analysis of variance and a Tukey test $(P<0.05)$. A "-" sign between numbers indicates that the intermediate awr genes are also deleted (i.e., $\Delta a w r 1-5$ is the quintuple deletion mutant strain). A "+" indicates complementation with the gene following the sign. A, $R$. solanacearum growth curves in eggplant 'Zebrina'. B, $R$. solanacearum growth curves in tomato 'Marmande' (black bars) and 'Hawaii 7796' (white bars). 
been previously shown to contribute to pathogenicity. To confirm the described phenotypes and better determine the contribution of each gene to bacterial fitness in planta, the quintuple mutant was complemented by sequentially introducing into its genome a single copy of $a w r 1, a w r 2$, or $a w r 5$. The strain bearing only $a w r 2$ restored bacterial multiplication to almost wildtype levels, whereas addition of awrl or awr5 to the quintuple mutant did not affect bacterial growth in the plant (Fig. 3A, right-most bars). These data correlate with the phenotypes of the single mutants and support a major role of $a w r 2$ in $R$. solanacearum virulence, with some functional redundancy of its paralogues.

\section{Some AWR effectors constrain}

\section{$R$. solanacearum pathogenicity on Arabidopsis.}

To better understand the role of AWR effectors in $R$. solanacearum virulence, in planta multiplication assays were also carried out in the alternative host Arabidopsis thaliana accession Col-0. Surprisingly, the strains deleted of four or five AWR multiplied much better than wild-type strain in Col-0 whereas growth of the wild type was almost undetectable (data not shown). Thus, contrary to what was observed in other hosts, the absence of AWR seemed to render the bacterium more proficient for multiplication in Arabidopsis. Because an advantage in multiplication often causes an increase in pathogenicity, we then performed the classical pathogenicity tests to better analyze these phenotypes (Fig. 4A). Plants were root inoculated with either the wild-type GMI1000 or $\Delta a w r 1-5$ mutant and development of wilting symptoms was recorded daily. Disease scoring showed increased virulence of the $\Delta a w r l-5$ strain compared with the wild strain, accelerating symptom appearance for approximately 2 days. Similar results were obtained with the sawrl-4 strain (not shown). This suggested that the presence of AWR effectors was limiting the capacity of the bacterium to multiply and cause disease in Arabidopsis. To better characterize this effect, we designed a gain-of-function assay introducing awr genes in P. syringae DC3000, an Arabidopsis pathogen naturally lacking them. AWR were heterologously expressed using the pEDV6 system and bacterial growth of the resulting strains was measured in Col-0 leaves (Fabro et al. 2011; Sohn et al. 2007). As expected, expression of several AWR effectors in this pathosystem caused a restriction in bacterial multiplication (Fig. 4B). This was particularly apparent when AWR4 and AWR5 were present, whereas AWR1 and AWR3 caused only a mild impact on pathogen progression. By contrast, the strain expressing AWR2 exhibited increased fitness in planta. These results support the previous observation that AWR2 plays a major role in virulence which, on natural hosts, is aided by a collective contribution of its paralogues. In addition, several AWR also seem to trigger specific plant recognition responses in A. thaliana, which is not a natural host for $R$. solanacearum, despite having been isolated from other crucifers. The same results were obtained when the effectors were expressed in the less virulent $P$. syringae pv. DC3000 derivative lacking the conserved effector locus instead of the wild type (not shown). Other studies have shown disparate responses of effector proteins on Arabidopsis and tomato plants (Lin et al. 2008; Milling et al. 2011). Unsurprisingly, Arabidopsis is a tremendous source of plant resistance toward pathogens and its study led to the discovery of the R protein, RRS1 (resistance to $R$. solanacearum 1 ) that confers resistance to $R$. solanacearum expressing PopP2 (Deslandes et al. 2003).

\section{Transient expression of AWR}

in $N$. benthamiana causes different levels of necrosis.

To determine whether AWR bacterial effectors are recognized in resistant plants, we used Agrobacterium-mediated tran- sient expression (hereafter, agroinfiltration) of AWR from an estradiol-inducible vector. We agroinfiltrated and scored for macroscopic cell death phenotypes in $N$. benthamiana, $N$. tabacum, and $N$. glutinosa plants, which are resistant to strain GMI1000. AWR5 production resulted in a rapid and marked
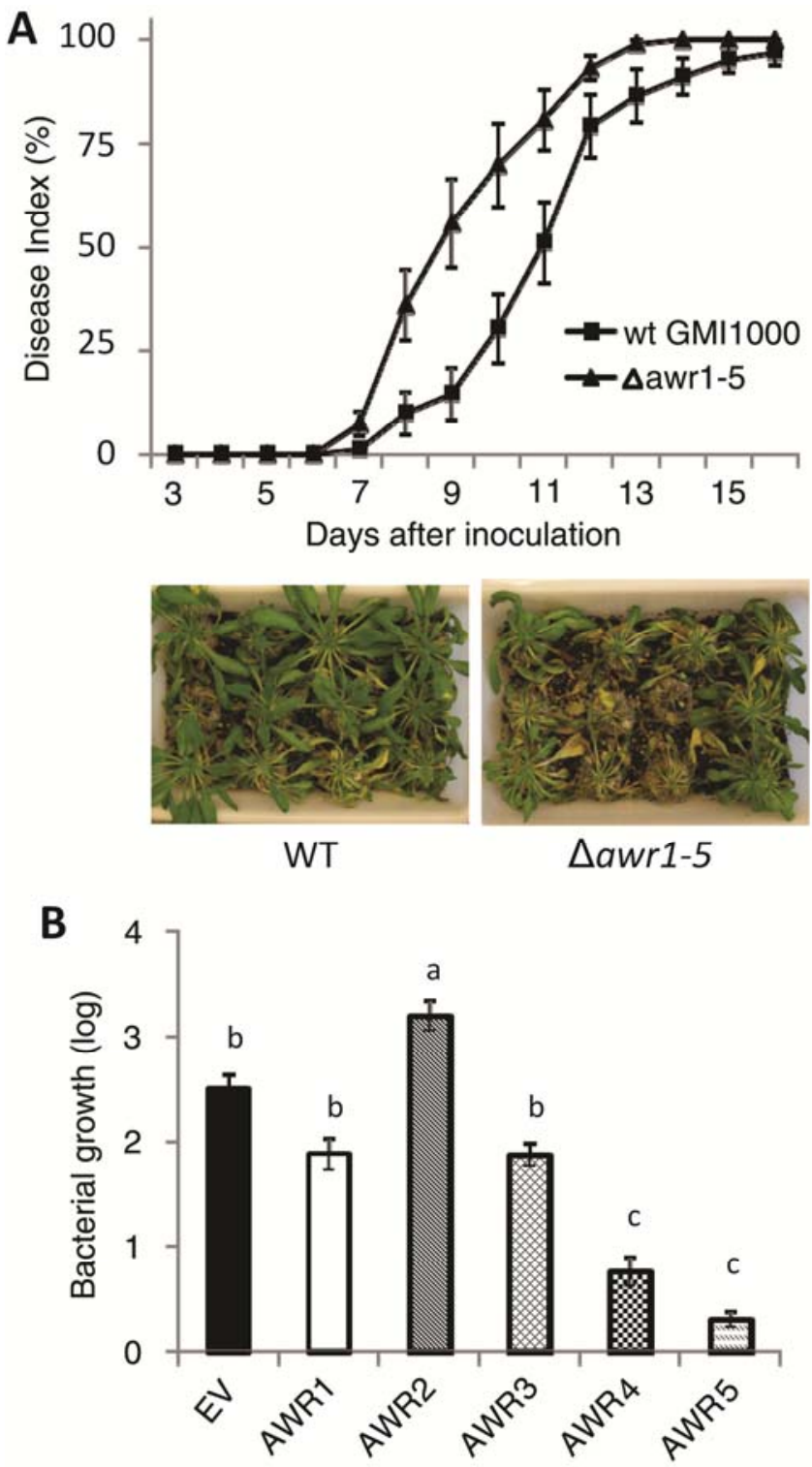

Fig. 4. Effect of alanine-tryptophan-arginine tryads (AWR) on bacterial pathogenicity on Arabidopsis thaliana. A, Pathogenicity test on A. thaliana Col-0 plants with the Ralstonia solanacearum $\Delta a w r 1-5$ multiple mutant strain and the control strain GMI1000 (WT). Plants were root inoculated and disease progression annotated daily according to wilting symptoms appearance: no wilting (0), 25\% wilted leaves (1), 50\% (2), 75\% (3), and dead plant (4). Values represent the mean of 12 biological replicas and their standard errors. Representative pictures were taken 10 days postinfection. Differences were statistically significant according to Student's $t$ test at $P<0.01$. The assay was repeated three times with similar results. B, Multiplication in A. thaliana Col-0 plants of Pseudomonas syringae DC3000 heterologously expressing AWR effectors. Strain DC3000 bearing the pEDV3 empty vector (EV), its hypersensitive response and pathogenicity $(h r p)$-deficient variant $(h r c C)$, and the strains that express each AWR were inoculated on leaves at $5 \times 10^{5} \mathrm{CFU} / \mathrm{ml}$ and recovered 3 days later to monitor bacterial growth. Bacterial multiplication is represented as the logarithm of recovered CFU per square centimeter with respect to the original inocula. Values represent the mean of four biological replicates. Statistically significant groups were calculated using a one-way analysis of variance with a Tukey test $(P<0.01)$. The experiment was repeated three times with similar results. 
necrosis in N. benthamiana leaves, and AWR1 and AWR2 produced a milder and less clear necrosis phenotype (Fig. 5A). Leaves expressing one of the two other AWR were indistinguishable from control leaves expressing $\beta$-glucuronidase (GUS) with the same inducible system. The full-length AWR5 protein was required for correct function or folding to trigger plant responses, because production of $\mathrm{N}$ - or $\mathrm{C}$-terminal or central protein fragments was insufficient to cause the necrosis phenotype (not shown). The rapid onset (approximately $24 \mathrm{~h}$ ) and the extent of the necrosis caused by AWR5 were reminiscent of that produced by the AvrA effector, known to trigger an HR in Nicotiana spp. (Fig. 5A, left) (Poueymiro et al. 2009).

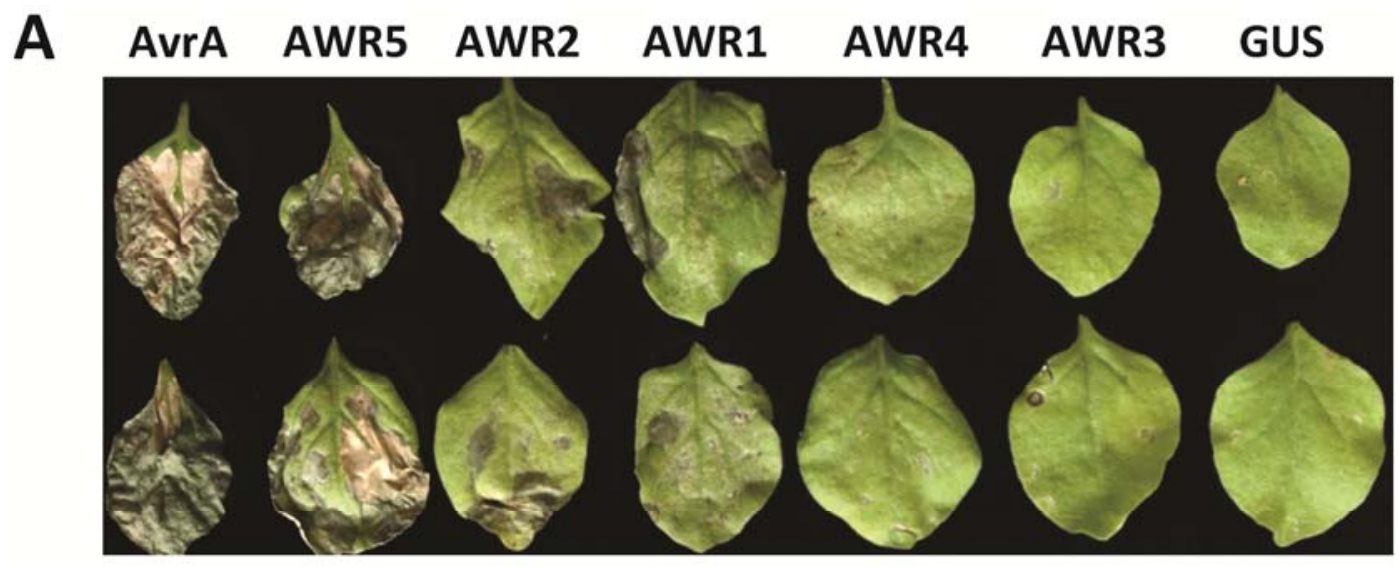

B

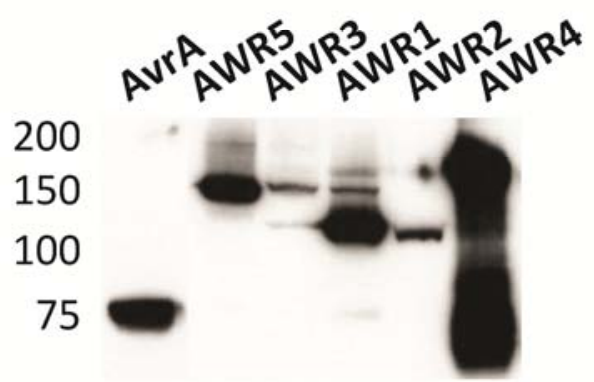

C

\begin{tabular}{l|c|c|c|} 
& $\mathrm{Nb}$ & $\mathrm{Ng}$ & $\mathrm{Nt}$ \\
\hline AWR5 & ++ & ++ & ++ \\
AWR2 & $+/-$ & + & $+/-$ \\
AWR1 & $+/-$ & - & $*$ \\
AWR3 & - & $*$ & $*$ \\
AWR4 & - & $+/-$ & -
\end{tabular}

\section{D}
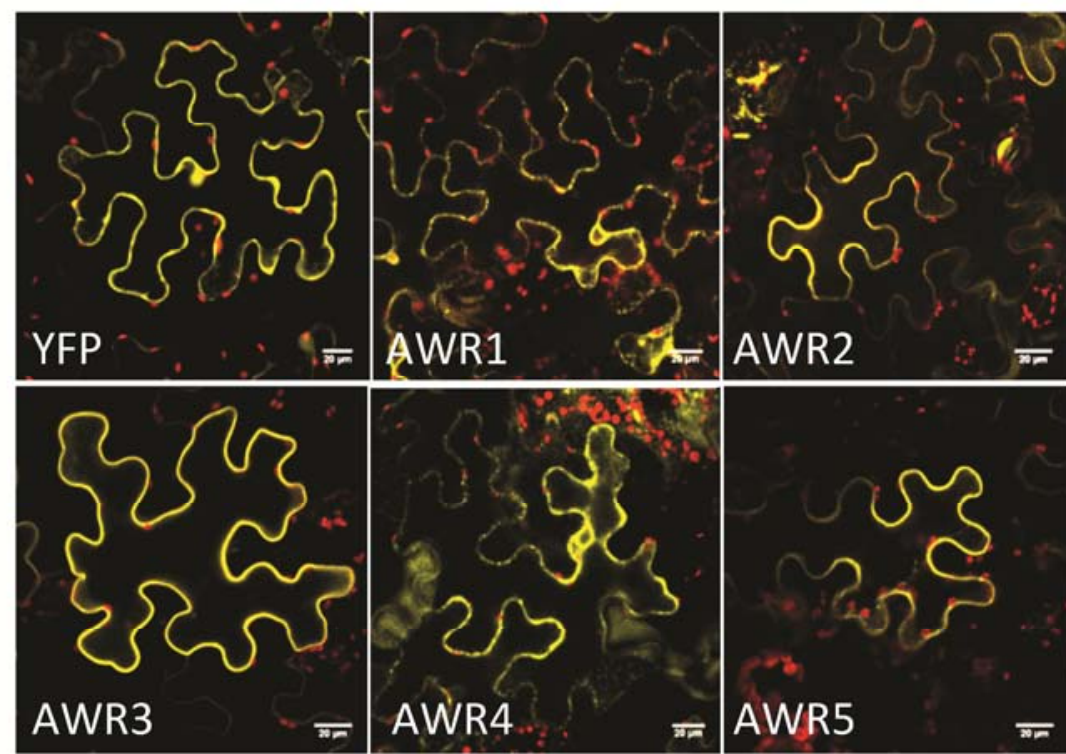

Fig. 5. Effects of AWR (alanine-tryptophan-arginine tryad) transient expression on nonhost Nicotiana plants. A, Photograph of representative Nicotiana benthamiana leaves expressing AWR or control proteins. Transient expression was performed using Agrobacterium tumefaciens as a vector to transfer estradiolinducible constructs from pAMP-PAT-derived plasmids. Full leaves were agroinfiltrated with the each construct. Pictures were taken 4 days after inoculation. The experiment was repeated four times with the same results. B, Immunoblotting of proteins transiently produced in $N$. benthamiana under an estradiolinducible promoter. Hemagglutinin (HA)-tagged proteins from total leaf extracts obtained at 6 to $8 \mathrm{~h}$ postinduction were immunodetected using an anti-HA antibody. C, Summary chart of the phenotypes caused by transient expression of AWR in N. benthamiana (Nb), $N$. tabacum ( $N t)$, and $N$. glutinosa $(\mathrm{Ng})$ plants. Average phenotypes observed from eight independent leaves are shown in a semiquantitative scale: $++=$ massive macroscopic necrosis, $+=$ clear necrosis variable in size and intensity, $+/-=$ minor necrosis present in only some infiltrated leaves, $-=$ appearance indistinguishable from control $\beta$-glucuronidase -expressing plants, and $*=$ not tested. D, AWR subcellular localization in $N$. benthamiana. Fluorescence confocal microscopy images of the 525 - to 550-nm (AWR-YFPv, yellow) and 610- to 700-nm (chloroplasts, red) spectra obtained after excitation with a 514-nm light. Pictures of representative cells expressing the bacterial effectors taken at $8 \mathrm{~h}$ postinduction are shown. As a reference, notice the cytoplasmatic and nuclear localization of the control yellow fluorescent protein (YFP). Bars correspond to $20 \mu \mathrm{m}$. 
Accumulation levels of all transiently expressed proteins were checked by immunoblot. Although proteins were expressed at different levels, it was clear that phenotypical responses triggered by AWR were not related to differences in their relative expression. Bands corresponding to the expected full-size proteins were detected for all constructs at $8 \mathrm{~h}$ postinduction (Fig. 5B). Phenotypical responses caused by AWR were also evalu- ated in two other nonhost tobacco species to check their specificity. The results are presented in Figure $5 \mathrm{C}$ in a semiquantitative scale. The phenotypes caused by AWR 5 and AWR 2 were apparent in all backgrounds and even stronger in N. tabacum. AWR1 and AWR4 showed minor necrosis on $N$. benthamiana and $N$. glutinosa, respectively (Fig. 5C). AWR3 had no macroscopic effect in any case, in spite of being readily detected by

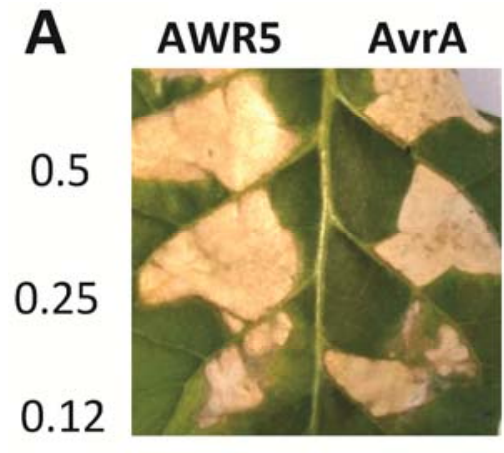

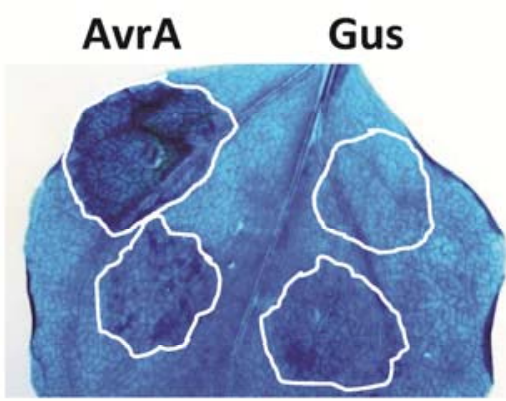

AWR5

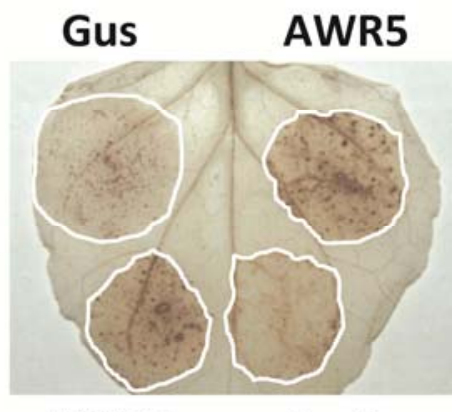

AWR5 AvrA

B
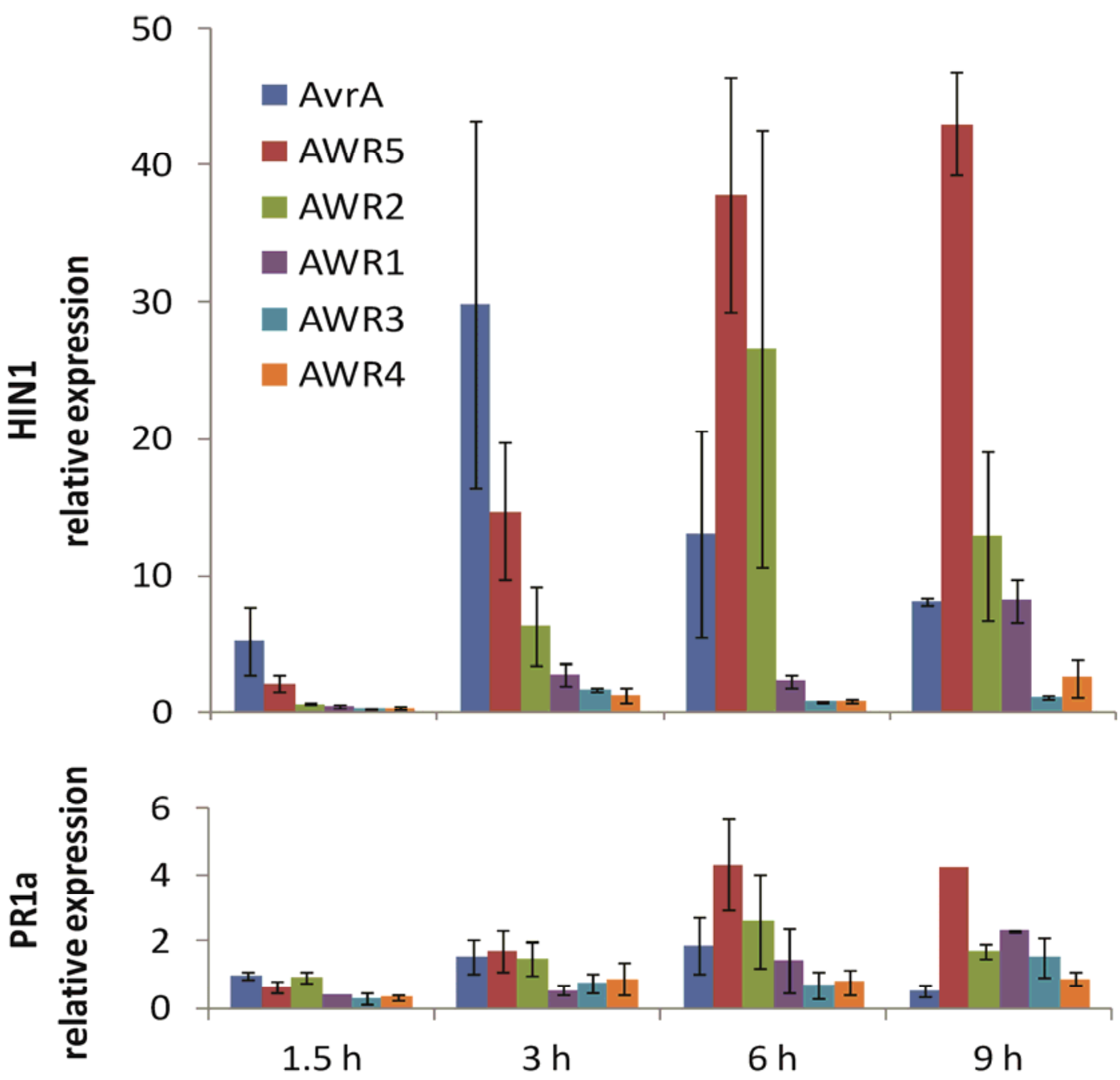

Fig. 6. Cell death phenotype caused by AWR5 is comparable with a hypersensitive response (HR). A, Pictures of Nicotiana tabacum leaves 48 h after infiltration with various concentrations of Agrobacterium tumefaciens bearing the awr5 and avrA genes (left). Left numbers indicate bacterial optical density at 600 nm of the inocula. Trypan blue staining of dead cells $26 \mathrm{~h}$ postinduction of agroinfiltrated leaf areas (central panel); GUS = $\beta$-glucuronidase. Diaminobenzidine staining of agroinfiltrated leaves showing $\mathrm{H}_{2} \mathrm{O}_{2}$ production at $8 \mathrm{~h}$ postinduction (right). B, AWR5 triggers an early induction of specific HR plant markers. Expression of HIN1 (HR-specific gene) and PRla (defense marker) was evaluated from RNA samples extracted at different time points from N. benthamiana leaves agroinfiltrated with constructs producing each AWR. Gene expression was normalized by the housekeeping gene tubulin and represented as foldinduction with respect to basal levels in control samples transiently expressing the GUS gene. Values shown are the mean of two biological replicates and their standard error. 
Western blot. It is worth mentioning that AWR5, which displays the strongest impact on plant physiology, is the one causing a major growth restriction when expressed in $P$. syringae. Interestingly, AWR2 and AWR5 are the only family members that have a very minor impact, if any, when ectopically overexpressed in tomato host plants (Supplementary Fig. S3). This reinforces the idea that the cell death produced in resistant plants is due to recognition and not a consequence of AWR function in planta. Such diversity in plant responses to AWR is surprising considering their similarity in the primary protein sequence. Similar results using other bacterial effectors have been described, further supporting the diverse host responses to AWR. A recent report where effector candidates from $X$. campestris, $P$. syringae, and $R$. solanacearum were transiently overexpressed in various plant species demonstrated that, although one-third produced visible phenotypes in at least one accession, none of them caused a reaction in all plants tested (Wroblewski et al. 2009). HR-like phenotypes have been interpreted as a programmed cell death elicited by avirulence factors, although recent publications discuss whether this HR might be a cause or a consequence of cascade signaling downstream of effector recognition (Coll et al. 2011).

To better understand the molecular basis of AWR-caused necrosis, we investigated subcellular localization of yellow fluorescent protein (YFP)-tagged AWR proteins. Agroinfiltration of some YFP-tagged AWR proteins in $N$. benthamiana leaves resulted in tissue collapse in early time points $(24 \mathrm{~h})$, indicating that YFP-tagged AWR proteins are functional. Confocal microscopy pictures taken at short intervals postinduction $(8 \mathrm{~h})$ are presented in Figure 5D. The images clearly show that fluorescence from all effector fusions was evenly localized in the cytoplasm, with some association to membranes (e.g., AWR4). In contrast to the free YFP protein, which is partially retained in the nucleus, none of the effectors targeted this compartment.

\section{AWR5 causes an HR when transiently expressed in tobacco species.}

To determine whether the cell death observed after AWR5 production in planta corresponded to an HR, we performed additional experiments by expressing this effector or the control AvrA protein at various levels. AvrA was previously described as triggering an HR response (Poueymiro et al. 2009). Serial infiltrations of different concentrations of Agrobacterium cells carrying either AWR5 or AvrA were performed on $N$. tabacum leaves, because the phenotypes were sharper in this plant and appeared earlier. Expression of both AWR5 or AvrA generated necrosis to the same level at similar time point ( $<24$ h) (Fig. 6A). To further compare cell death phenotypes caused by AvrA and AWR5, we performed trypan blue staining of the infected leaf tissues to visualize dead cells (Keogh et al. 1980), and diaminobenzidine (DAB) staining that results in brown deposits upon reaction with H202 (Thordal-Christensen et al. 1997). Agroinfiltration of AWR5 triggered a cell-death phenotype and induced higher accumulation of H202 compared with AvrA in N. benthamiana (Fig. 6A, right panels). These results imply that the AWR5-triggered cell death response in nonhost tobacco plants resembles classical HR (Torres, 2010). To better characterize the observed responses at the molecular level, we measured the expression of defense-related marker genes that are induced during development of HR in $N$. benthamiana. HIN1 was chosen as a specific molecular marker of HR in tobacco, because its expression is highly induced during incompatible interactions and strictly restricted to the challenged tissue (Gopalan et al. 1996; Kiba et al. 2003). Transcript levels of HIN1 and pathogen-response (PR) genes were measured by real-time quantitative reverse-transcriptionmediated polymerase chain reaction (RT-PCR) by using total
RNA samples isolated from agroinfiltrated $N$. benthamiana leaves. The results of these experiments are presented in Figure $6 \mathrm{~B}$ as fold-induction with respect to basal expression levels from leaves expressing the control GUS transcripts. A marked increase of the HIN1 transcripts was already apparent $3 \mathrm{~h}$ after estradiol induction of effectors, causing clear HR-like phenotypes (AvrA or AWR5), and this high expression extended to 6 and $9 \mathrm{~h}$ postinduction. At these late time points, HINl was also induced at levels comparable with those caused by AvrA and by AWR2 or AWR1, which caused milder necrosis on tobacco. The AWR effectors (AWR3 and AWR4) producing no macroscopic phenotype when agroinfiltrated did not activate HRresponsive genes (Fig. 6B). By contrast, expression of the PR1a defense gene was almost unaltered $(<$ twofold changes compared with AvrA) for any of the strains tested. For AWR2, AWR5, and the control strains, RNA levels of the defense-responsive PR1b or the HR-responsive hsr203j (Kiba et al. 2003; Pontier et al. 1998) were comparable with HINI and PRla (data not shown). Gene $h s r 203 j$ was tested because it had been described as specifically induced in tobacco tissues inoculated with strain GMI1000 (incompatible interaction) and undetectable upon challenge with strain K60 (compatible interaction) or a nonpathogenic hrp mutant strain (Pontier et al. 1998). Thus, induction of the specific molecular markers perfectly correlated with the phenotypes observed in planta.

From our results, we infer that an HR only appears when an expression threshold of marker genes is reached. This threshold implies a minimum transcript level at a certain time (approximately 30 -fold before $6 \mathrm{~h}$ for HIN1), so that lower levels or even comparable levels but at later times are not sufficient to mount programmed cell death. Along the same line, it has been suggested that common genes are involved in both compatible and incompatible responses against pathogens, with the differential timing determining the outcome (Hu et al. 2008; Tao et al. 2003). Taken together, our phenotypic and molecular analyses prove that AWR5 can trigger an HR when overexpressed in Nicotiana spp. It is noteworthy that this response is equivalent to that caused on tobacco leaves with AvrA or with the whole bacterial strain GMI1000 (Kiba et al. 2003), suggesting that AWR effectors can play a role in restriction of the $R$. solanacearum host range.

\section{Conclusion.}

$R$. solanacearum is a devastating pathogen that requires T3SS to successfully infect plants (Boucher et al. 1987). It is one of the bacterial pathogens with the highest number of predicted T3E (Cunnac et al. 2010; Kay and Bonas, 2009; Mukaihara et al. 2010) but most of their functions remain unknown, contrary to other pathogens such as $P$. syringae or the xanthomonads. Among all putative effectors found in $R$. solanacearum, we have focused here on the characterization of a multigenic family called AWR. Our results demonstrate that the encoded proteins in GMI1000 are secreted through the T3SS and are required for full virulence of the pathogen on natural hosts. It is interesting to note that AWR1 translocation to plant cells had been undetected using a $c y a A$ reporter fusion but it was proven here through protein secretion studies. This discrepancy is unlikely due to the fact that proteins from different strains (RS1000 and GMI1000) were analyzed, because the N terminal (first 50 amino acids) of the two proteins, where secretion signals lay, is $94 \%$ identical. Rather, we favor the hypothesis that type III-dependent secretion studies are a more sensitive test than translocation of $c y a A$ fusions, which may be prone to false negatives.

The high redundancy of effector repertoires has been interpreted as a means to use particular combinations for effective colonization of different hosts (Cunnac et al. 2004a; Kvitko et 
al. 2009). In the case of AWR, one of them (AWR2) plays a major role in pathogenicity, regardless of the plant host, whereas the other members of the family act synergistically, reinforcing this function. Our deletion and complementation experiments suggest that the role of each family member in virulence is somewhat redundant. For example, a single AWR (AWR2) confers wild-type pathogenicity on eggplant whereas a single mutant for the same AWR shows higher pathogenicity than a mutant deleted for all the $a w r$ genes. These features of the AWR family suggest that $R$. solanacearum virulence involves a small number of effectors with a key effect and many effectors with a weak, additive contribution. This seems to be true for the whole GMI1000 effector repertoire, out of which only AWR2 and RSp0304 deletion mutants showed decreased pathogenicity on tomato (Cunnac et al. 2004b).

Contrary to the similar contribution of AWR to pathogenicity on diverse hosts, we have found a high degree of specificity in the responses triggered by AWR in different plants. AWR5 - and, to a lesser extent, AWR2 and AWR1 - triggered the major responses in nonhost tobacco plants, whereas Arabidopsis plants showed some recognition of AWR5 and AWR4. Thus, AWR exhibit functional diversification, as was recently described by another $R$. solanacearum type III effector family showing specialized roles in pathogenicity on different plant hosts (Remigi et al. 2011). Our results in A. thaliana are especially interesting. In this plant host, the presence of AWR seems to restrict $R$. solanacearum virulence, as revealed by the increased pathogenicity and multiplication of the $\Delta a w r 1-5$ strain. It seems logical that the bacterium is not fully pathogenic in this plant, which is never confronted with the pathogen in nature. However, when the role of each AWR was analyzed separately by a gain-of function approach in the heterologous pathogen $P$. syringae, we obtained somehow conflicting results. As mentioned, AWR5 and AWR4 showed this capacity to restrict bacterial multiplication but AWR2 expression clearly promoted the pathogenicity of $P$. syringae. Thus, the outcome of the interaction of $R$. solanacearum with $A$. thaliana is the result of antagonistic interactions specific for each effector.

AWR2 is one of the main contributors to $R$. solanacearum virulence on different hosts, suggesting conservation in its targets, but it is also recognized by the plant surveillance system. This dual role in virulence and resistance has already been documented for some bacterial effector proteins and been interpreted in the light of plant-pathogen coevolution, which results in compatible and incompatible interactions (SchulzeLefert and Panstruga 2010). For instance, AvrBsT from $X$. campestris pv. vesicatoria is recognized in pepper and $N$. benthamiana plants whereas it enhances bacterial growth in tomato plants (Kim et al. 2010). Similarly, evolutionary and virulenceavirulence studies with effectors of the YopJ/HopZ effector superfamily have shown their functional diversification in wideranging coevolutionary interactions (Lewis et al. 2011). The distinct functions of each AWR in virulence and avirulence likely contribute to host adaptation, explaining the high degree of conservation of these effectors in $R$. solanacearum.

AWR are also present in other plant-pathogenic strains with emerging importance such as the rice pathogen B. glumae, other Burkholderia strains, Acidovorax avenae infecting cucurbitaceae or poaceae and some Xanthomonas pathovars causing disease in rice, pepper, tomato, brasicaceae, citrus, or even a bacterial wilt in banana (Ham et al. 2010; Mole et al. 2007; Smith et al. 2008; Viallard et al. 1998; Willems et al. 1992). The long evolution suffered by this ancestral family and the disparate contexts in which it functions may have facilitated the functional diversification that we have observed for its members. In addition, AWR homologues are also present in the mammal pathogen B. pseudomallei, the causal agent for melioidosis (Wuthiekanun and Peacock 2006), whose T3SS is similar to that of $R$. solanacearum (Rainbow et al. 2002). It would be interesting to evaluate the role of AWR in this pathogen also capable of infecting tomato plants (Lee et al. 2010) because, in $P$. aeruginosa, some virulence factors are important for pathogenesis on both plant and animal hosts (Rahme et al. 1997). Indeed, effectors from plant pathogens such as HopAO1 from $P$. syringae have already been shown to share the same function with their homologues in Salmonella and Shigella spp. (Shan et al. 2007).

In this work, we characterized the physiological impact of AWR on different plant species. Plant localization did not give clues to the events that follow effector translocation in planta. Experiments are under way to identify and biochemically characterize the molecular targets of AWR in host and nonhost plants to broaden our knowledge of the virulence strategies developed by $R$. solanacearum to provoke bacterial wilt disease.

\section{MATERIALS AND METHODS}

\section{DNA cloning and molecular biology techniques.}

TOPO or GATEWAY BP/LR recombinational clonings were achieved according to the supplier's manuals (Invitrogen Life Technologies Ltd. Paisley, U.K.). Some of the genes were amplified with and without STOP codon or, alternatively, this codon was inserted or deleted afterward with the QuikChange XL-Site-directed mutagenesis kit (Stratagene, La Jolla, CA, U.S.A.). PCR amplifications were typically performed with the proofreading Pfx DNA polymerase (Invitrogen) in a $50 \mu \mathrm{l}-$ mix containing $0.3 \mathrm{mM}$ each $\mathrm{dNTP}, 0,6 \mathrm{mM}$ each primer, 2

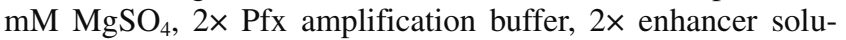
tion, $0.2 \mu \mathrm{g}$ of DNA, and 1.25 U of Pfx DNA polymerase. Amplification cycles were always performed approximately $5^{\circ} \mathrm{C}$ below the melting temperature of the primers employed. To clone in pGEM-T, 5' A-overhangs were added to PCR products by incubating $6 \mu \mathrm{l}$ of the PCR with $1 \mu \mathrm{l}$ of $10 \times$ reaction buffer containing $\mathrm{MgCl}_{2}, 0.2 \mathrm{mM}$ dATP, and $5 \mathrm{U}$ of GoTaq polymerase at $70^{\circ} \mathrm{C}$ for $20 \mathrm{~min}$. Verification of PCR was routinely carried out with the nonproofreading GoTaq DNA polymerase, as recommended by the supplier (Promega Corp.). For all clonings, DNA fragments were electrophoresed in agarose gels in Tris-acetate EDTA containing SYBR Safe DNA gel stain (Invitrogen), and bands were excised and purified with the Expin GEL SV (GeneAll Biotechnology Co., Ltd Seoul, Korea), introduced to the final vector by Gateway recombination or ligation, and transformed into Escherichia coli. Plasmids were then recovered with the Exprep Plasmid SV kit (GeneAll) for clone verification with restriction enzymes (New England) and sequencing with BigDye terminator v3.1 (Life Technologies Ltd., Paisley, U.K.) followed by further cloning if required.

For the generation of the $R$. solanacearum deletion mutant strains with the cre-lox system, we amplified $1 \mathrm{~Kb}$-long $5^{\prime}(\mathrm{L})$ and $3^{\prime}(\mathrm{R})$ flanking regions of the coding sequence of interest and cloned the fragments in pGEM-T (Invitrogen). Inner EcoRI and SacI restriction sites in 2139L (GAATTC $>$ GATT TC) and 0099R (GAGCTC>GAGCAC) were mutagenized with the QuikChange XL site-directed mutagenesis kit before cloning into the final pCM351 vector. All generated plasmids are described in Supplementary Table S2. Clones without stop codons were used for expression with C-terminal fusions, unless otherwise stated. All primers used in this study for cloning or RT-PCR are listed in Supplementary Table S3.

\section{Bacterial strains, plant material, and growth conditions.}

$E$. coli cells were routinely grown in Luria-Bertani (LB) medium at $37^{\circ} \mathrm{C}$. Agrobacterium tumefaciens and $P$. syringae 
were grown in YEB or L-media, respectively, at $30^{\circ} \mathrm{C}$. $R$. solanacearum cells were grown in complete B medium or in minimal medium (MM) supplemented with $20 \mathrm{mM}$ glutamate at $28^{\circ} \mathrm{C}$ (Boucher et al. 1987). For secretion studies, bacteria were grown at $25^{\circ} \mathrm{C}$ in $\mathrm{MM}$ containing $10 \mathrm{mM}$ glutamate and $10 \mathrm{mM}$ sucrose as a carbon source. Congo red was also added to the cultures, at $100 \mu \mathrm{g} / \mathrm{ml}$, because it is known to promote or stabilize secretion (Bahrani et al. 1997; Gueneron et al. 2000). Antibiotics were used for selection at the following concentrations: ampicillin at $100 \mu \mathrm{g} / \mathrm{ml}$, chloramphenicol at $30 \mu \mathrm{g} / \mathrm{ml}$, gentamicin at $15 \mu \mathrm{g} / \mathrm{ml}$ (10 in plates or 5 in liquid cultures for Ralstonia spp.), kanamycin at $50 \mu \mathrm{g} / \mathrm{ml}$, rifampicin at 25 $\mu \mathrm{g} / \mathrm{ml}$, spectinomycin at $40 \mu \mathrm{g} / \mathrm{ml}$, and tetracycline at $10 \mu \mathrm{g} / \mathrm{ml}$ (5 in Ralstonia liquid cultures).

The plants used for this work were 5-week-old Arabidopsis thaliana Columbia 0; 4-week-old $N$. benthamiana; 5-week-old N. glutinosa; 6-week-old N. tabacum 'Bottom special'; 4- to 5week-old Lycopersicon esculentum Marmande, 'Bonnie Best', and Hawaii 7996; and 5-week-old Solanum melongena Zebrina. All plants were grown in long-day light conditions, except for A. thaliana, grown in short-day conditions with constant temperature at $22^{\circ} \mathrm{C}$ and humidity approximately $60 \%$. After Agrobacterium sp. infiltrations, plants were kept in the same conditions whereas, after Ralstonia or Pseudomonas sp. inoculations, they were incubated in a chamber with constant light conditions and a fixed temperature of 28 and $25^{\circ} \mathrm{C}$, respectively.

\section{Bacterial transformation.}

$\mathrm{RbCl}$-chemically competent E. coli cells were transformed by the heat-shock method, as described by Sambrook and Russell (2001). MACH-1 cells (Invitrogen) were used as recipients for all clonings except for the GATEWAY-carrying plasmids, which were always transformed in the ccdB-resistant $E$. coli gyrA462 mutant strain (Bernard et al. 1994). Agrobacterium tumefaciens GV3103 was transformed by electroporation in a 2 -mm cuvette $(2.5 \mathrm{Kev}, 25 \mu \mathrm{F}, 186 \Omega)$ with $2 \mu \mathrm{l}$ of DNA, incubated for phenotypic expression during 3 to $6 \mathrm{~h}$, plated, and then incubated overnight in LB with suitable antibiotics. A standard triparental mating procedure (Sohn et al. 2007) was used to transfer plasmids from E. coli to P. syringae DC3000 using the $E$. coli-carrying pRK2013 as a helper strain. $R$. solanacearum GMI1000 natural transformations were performed as described (Boucher et al. 1985). For deletion mutagenesis in $R$. solanacearum with the cre-lox system (Marx and Lidstrom 2002), pCM351-derived plasmids were introduced in $R$. solanacearum by natural transformation and mutants resistant to gentamicin were recovered. The resistance gene flanked by lox $\mathrm{P}$ sites was finally excised by electroporating the strain $(2.5$ $\mathrm{Kv}, 50 \mu \mathrm{F}, 129 \Omega$, 2-mm cuvettes) with pSG15, which harbors the cre recombinase, and growing the transformants for 2 days at $30^{\circ} \mathrm{C}$ without antibiotics to cure the pSG15 plasmid. Deletion of all AWR genes was confirmed by hybridization of genomic DNA extracted from the different mutant strains onto the genomic microarray from strain GMI1000 as described by Guidot and associates (2007). For each mutant, T3SS functionality was validated by infiltration in $N$. benthamiana plants to verity HR caused by ETI.

\section{Agrobacterium-mediated protein expression in planta.}

Transient Agrobacterium-mediated protein expression was performed in $N$. benthamiana, N. tabacum, and N. glutinosa. For this, A. tumefaciens overnight-cultured cells were centrifuged and resuspended in $10 \mathrm{mM} \mathrm{MgCl}_{2}, 10 \mathrm{mM} \mathrm{MES}$, and $150 \mu \mathrm{M}$ acetosyringone for inoculation at an optical density at $600 \mathrm{~nm}$ of 0.5 to 0.8 , then incubated for 1 to $2 \mathrm{~h}$ at room temperature. A strain harboring the P19 vector was co-infiltrated in most cases to avoid plant-silencing mechanisms. Bacterial strains were hand inoculated with a needle-free syringe in plant leaves from different plants. If required, protein expression was induced by painting the leaves $36 \mathrm{~h}$ postinfiltration with $5 \mu \mathrm{M}$ estradiol and some Silwet L-77. For protein detection, three leaf discs of $6 \mathrm{~mm}$ were harvested at 3 to $6 \mathrm{~h}$ postinduction and homogenized in liquid nitrogen. Samples were subjected to standard Western-blot analysis as described by Sambrook and Russell (2001) using polyvinylidene difluoride (PVDF) membranes, an already HRP-conjugated anti-HA antibody (1:4000; F. Hoffmann, La Roche Ltd., Basel, Switzerland), Amersham Hypercassette films (GE Healthcare, Piscataway, NJ, U.S.A.), and Immobilon ECL (Billerica, MA, U.S.A.). For AWR subcellular localization, disc samples mounted in water were observed under a confocal microscope (Leica DMIRE2, Ryswyk, The Netherlands) with the 525- to 550-nm laser for YFPv and the 610- to 700-nm laser for chloroplasts. Images were taken with the $\times 40$ objective (Leica confocal software) and processed with the Fiji software. For trypan blue staining, Agrobacterium-infiltrated leaves were boiled in a trypan blue-lactophenol solution with ethanol and cleared in chloral hydrate solution as described (Keogh et al. 1980). For DAB staining, Agrobacterium-infiltrated leaves were incubated overnight at room temperature with DAB as previously described (Thordal-Christensen et al. 1997).

\section{Pathogenesis assays in planta.}

$R$. solanacearum multiplication in planta was measured similarly to what is used in the Pseudomonas community to assay the effect of T3E proteins in bacterial virulence (Sohn et al. 2007), with a procedure adapted from Macho and associates (2010). Briefly, plant leaves were hand inoculated with fresh bacteria at $10^{5} \mathrm{CFU} / \mathrm{ml}$ (tomato and eggplant) or $10^{6}$ $\mathrm{CFU} / \mathrm{ml}$ (col-0) with a $1-\mathrm{ml}$ blunt syringe. Pseudomonas strains were inoculated at $5 \times 10^{5} \mathrm{CFU} / \mathrm{ml}$ in Arabidopsis plants. Bacteria were recovered in $200 \mu \mathrm{l}$ of water at 0 and $3 \mathrm{dpi}$ ( 4 dpi for Arabidopsis and Hawaii tomato plants inoculated with Ralstonia spp.). For each strain, two biological replicates were taken at 0 dpi and four at 3 to $4 \mathrm{dpi}$ (each containing four discs of $5 \mathrm{~mm}$ in diameter from independent leaves). Bacterial suspensions were serially 10 -fold diluted and plated in replicas on rich $\mathrm{B}$ medium plates. CFU were counted and bacterial growth calculated as the recovered CFU per square centimeter with respect to the original inoculums. Results were validated with the one-way analysis of variance test (Tukey post-analysis test) with the GraphPad software statistics package. HR assays were performed as described (Poueymiro et al. 2009) by infiltrating solutions of $1.5 \times 10^{8}$ bacteria $/ \mathrm{ml}$ obtained from fresh colonies on adult Nicotiana plants grown in a greenhouse.

For $R$. solanacearum pathogenicity tests by soil inoculation, 5-week-old Arabidopsis plants grown in Jiffy-7 peat pellets were root cut, incubated with a bacterial solution at $10^{8}$ $\mathrm{CFU} / \mathrm{ml}$ for $30 \mathrm{~min}$, and transferred to the growth chamber again. Symptom appearance was recorded independently for each plant according to a wilting scale of 0 to $4(0=$ no wilting; $1=25,2=50$, and $3=75 \%$ leaves wilted; and $4=$ death).

\section{RNA obtention and quantitative RT-PCR.}

Two independent biological replicas of six tubes containing six leaf discs from six different plants expressing each AWR and control proteins were harvested at different time points after induction and they were homogenized in liquid nitrogen. RNA was extracted from the samples (NucleoSpin RNA plant; Macherey-Nagel, Düren, Germany) according to the manufacturer's protocol and quantified afterward. Approximately $2 \mu \mathrm{g}$ of total RNA was subjected to retrotranscription with anchored oligo- $(\mathrm{dT})_{18}$ primers (Transcriptor first strand cDNA synthesis 
kit; Roche). For quantitative real-time PCR, a Light Cycler 480 (Roche) with SYBR Green chemistry was used with two technical replicas. Tubulin was used as a housekeeping gene to normalize samples for the amount of RNA. The results were presented with respect to the transcript levels of the gus control gene that should not interfere with expression of the genes assessed.

\section{Protein purification, immunodetection, and secretion studies.}

For secretion studies, overnight-grown $R$. solanacearum bacteria were inoculated at $2 \times 10^{8} \mathrm{cells} / \mathrm{ml}$ in $20 \mathrm{ml}$ of $\mathrm{MM}$ containing $10 \mathrm{mM}$ glutamate and $10 \mathrm{mM}$ sucrose as a carbon source. Congo red was also added to the cultures at $100 \mu \mathrm{g} / \mathrm{ml}$ to promote or stabilize secretion (Gueneron et al. 2000). Cultures were grown at $25^{\circ} \mathrm{C}$ for 12 to $18 \mathrm{~h}$ and bacteria were separated from the medium by centrifugation at $4,000 \times g$ for $10 \mathrm{~min}$ at room temperature. Cells were resuspended in $1 \mathrm{ml}$ of phosphate-buffered saline (PBS) buffer, lysed by sonication, and mixed 1:1 with $2 \times$ Laemmli sample loading buffer. Culture supernatants were filtered through a $0.22-\mu \mathrm{m}$-pore membrane to eliminate residual cells, which was confirmed by plating $200 \mu \mathrm{l}$ into a rich agar plate. Proteins were then precipitated from the medium by adding one volume of $25 \%$ trichloroacetic acid and incubating overnight at $4^{\circ} \mathrm{C}$. Precipitated proteins were pelleted by centrifugation at $6,000 \times g$ for $30 \mathrm{~min}$ at $4^{\circ} \mathrm{C}$, washed twice in cold $90 \%$ acetone, dried, resuspended in 100 $\mu \mathrm{l}$ PBS, mixed 1:1 with $2 \times$ Laemmli buffer, and subjected to Western-blot analysis.

\section{Sodium dodecyl sulfate polyacrylamide gel electrophoresis and Western-blot analysis.}

Samples were routinely mixed 1:1 with Laemmli buffer $(0.2$ $\mathrm{M}$ dithiothreitol, 0.125 Tris- $\mathrm{HCl}$ [pH 7.5], 4\% sodium dodecyl sulfate, and $20 \%$ glycerol), loaded into $1-\mathrm{mm}$-wide $7.5 \%$ acrylamide gels, and migrated for 1 to $3 \mathrm{~h}$ at 120 to $170 \mathrm{~V}$ (Bio-Rad, Munich). Proteins were transferred to PVDF membranes (Amersham, Bucks, U.K.) overnight at $4^{\circ} \mathrm{C}(30 \mathrm{~V})$ or $1 \mathrm{~h}$ at room temperature $(100 \mathrm{~V})$. For HA-tag detection, membranes were incubated overnight at $4^{\circ} \mathrm{C}$ or 3 to $5 \mathrm{~h}$ at room temperature with anti-HA rat monoclonal antibody (clone 3F10; Roche) already conjugated to HRP (diluted 1/4000). For YFP detection, membranes were incubated for $1 \mathrm{~h}$ at room temperature with anti-green fluorescent protein rabbit polyclonal antibody (Santa Cruz Biotechnology Inc., Santa Cruz, CA, U.S.A.) already conjugated to HRP (diluted 1/1000). For detection, immobilon ECL (Millipore) and a LAS-4000 mini system (Fujifilm, Tokyo) were used, or Amersham Hypercassette films (GE Healthcare) developed with silver nitrate in a Medical Film Processor FPM-100A (Fujifilm).

\section{In silico analysis of the AWR gene family.}

DNA and protein BLAST analyses were performed separately for all AWR sequences (nonredundant protein sequences) to find related members in other Ralstonia strains or other bacterial species. InterPro scan was used as an integrated database for protein "signatures" prediction of AWR. The PHYRE database was used for three-dimensional predictions. To obtain similarity and identity values between AWR proteins and their representative homologs in other species, we used the EMBOSS Needle online software that performs a global alignment of two given sequences. Protein sequences that showed similarity to AWR ( $e$ value $<0.01$ with a sequence coverage $\geq 30 \%$ or sequence identity $\geq 20 \%$ with higher $e$ values) were aligned using the MAFFT program (E-INS-i parameter suitable for sequences with multiple conserved domains and long gaps) and edited with GBlocks (allowing smaller final blocks, smaller gap position, and less strict flanking positions). Phylogenetic analysis was performed by the MrBayes program (Huelsenbeck and Ronquist 2001), based in a Bayesian estimation, with a stringency convergence $<0.01$, and contrasted with PhyML, based in a maximum-likelihood estimation (100 trials performed). All sequences used for tree constructions and their access number are described in Supplementary Table S2.

\section{ACKNOWLEDGMENTS}

We thank C. Boucher, S. Rivas, and N. Sánchez-Coll for their advice, support, and stimulating discussions; A. Sebé and M. Riutort for their valuable assistance with phylogenetic analyses; and E. Washington for kindly providing plasmid pMDC7-Citrine. M. Solé held a Formación de Personal Investigador Ph.D. fellowship from the Ministerio de Ciencia, Tecnología e Innovación (MICINN) and an EMBO (European Molecular Biology Organization) short-term fellowship. This work was supported by grants SGR0052 and CONES2010-0030 from the Comissionat per Universitats i Recerca of the Generalitat de Catalunya and HF2008-0021, BIO200609019 and AGL2010-21870 from the MICINN.

\section{LITERATURE CITED}

Alfano, J. R., and Collmer, A. 2004. Type III secretion system effector proteins: Double agents in bacterial disease and plant defense. Annu. Rev. Phytopathol. 42:385-414.

Angot, A., Peeters, N., Lechner, E., Vailleau, F., Baud, C., Gentzbittel, L., Sartorel, E., Genschik, P., Boucher, C., and Genin, S. 2006. Ralstonia solanacearum requires F-box-like domain-containing type III effectors to promote disease on several host plants. Proc. Natl. Acad. Sci. U.S.A. 103:14620-14625.

Arnold, D. L., Pitman, A., and Jackson, R. W. 2003. Pathogenicity and other genomic islands in plant pathogenic bacteria. Mol. Plant Pathol. 4:407-420.

Attree, O., and Attree, I. 2001. A second type III secretion system in Burkholderia pseudomallei: Who is the real culprit? Microbiology 147:3197-3199.

Bahrani, F. K., Sansonetti, P. J., and Parsot, C. 1997. Secretion of Ipa proteins by Shigella flexneri: Inducer molecules and kinetics of activation. Infect. Immun. 65:4005-4010.

Bernard, P., Gabant, P., Bahassi, E. M., and Couturier, M. 1994. Positiveselection vectors using the F plasmid ccdB killer gene. Gene 148:71-74

Block, A., Li, G., Fu, Z. Q., and Alfano, J. R. 2008. Phytopathogen type III effector weaponry and their plant targets. Curr. Opin. Plant Biol. 11:396-403.

Boucher, C., Barberis, P., Trigalet, A., and Demery, D. 1985. Transposon mutagenesis of Pseudomonas solanacearum: Isolation of TnS-induced virulent mutants. J. Gen. Microbiol. 131:2449-2457.

Boucher, C. A., Van Gijsegem, F., Barberis, P. A., Arlat, M., and Zischek, C. 1987. Pseudomonas solanacearum genes controlling both pathogenicity on tomato and hypersensitivity on tobacco are clustered. J. Bacteriol. 169:5626-5632.

Buttner, D., and He, S. Y. 2009. Type III protein secretion in plant pathogenic bacteria. Plant Physiol. 150:1656-1664.

Carney, B. F., and Denny, T. P. 1990. A cloned avirulence gene from Pseudomonas solanacearum determines incompatibility on Nicotiana tabacum at the host species level. J. Bacteriol. 172:4836-4843.

Castresana, J. 2000. Selection of conserved blocks from multiple alignments for their use in phylogenetic analysis. Mol. Biol. Evol. 17:540 552.

Coll, N. S., Epple, P., and Dangl, J. L. 2011. Programmed cell death in the plant immune system. Cell Death Differ. 18:1247-1256.

Cui, H., Xiang, T., and Zhou, J. M. 2009. Plant immunity: A lesson from pathogenic bacterial effector proteins. Cell Microbiol. 11:1453-1461.

Cunnac, S., Boucher, C., and Genin, S. 2004a. Characterization of the cisacting regulatory element controlling $\mathrm{HrpB}$-mediated activation of the type III secretion system and effector genes in Ralstonia solanacearum. J. Bacteriol. 186:2309-2318.

Cunnac, S., Occhialini, A., Barberis, P., Boucher, C., and Genin, S. 2004b Inventory and functional analysis of the large Hrp regulon in Ralstonia solanacearum: Identification of novel effector proteins translocated to plant host cells through the type III secretion system. Mol. Microbiol. 53:115-128.

Cunnac, S., Chakravarthy, S., Kvitko, B. H., Russell, A. B., Martin, G. B., and Collmer, A. 2010. Genetic disassembly and combinatorial reassembly identify a minimal functional repertoire of type III effectors in Pseudomonas syringae. Proc. Natl. Acad. Sci. U.S.A. 108:2975-2980. 
Dean, P. 2011. Functional domains and motifs of bacterial type III effector proteins and their roles in infection. FEMS (Fed. Eur. Microbiol. Soc.) Microbiol. 35:1100-1125.

Deslandes, L., Olivier, J., Peeters, N., Feng, D. X., Khounlotham, M., Boucher, C., Somssich, I., Genin, S., and Marco, Y. 2003. Physical interaction between RRS1-R, a protein conferring resistance to bacterial wilt, and PopP2, a type III effector targeted to the plant nucleus. Proc. Natl. Acad. Sci. U.S.A. 100:8024-8029.

Fabro, G., Steinbrenner, J., Coates, M., Ishaque, N., Baxter, L., Studholme, D. J., Korner, E., Allen, R. L., Piquerez, S. J., Rougon-Cardoso, A., Greenshields, D., Lei, R., Badel, J. L., Caillaud, M. C., Sohn, K. H., Van den Ackerveken, G., Parker, J. E., Beynon, J., and Jones, J. D. 2011. Multiple candidate effectors from the oomycete pathogen Hyaloperonospora arabidopsidis suppress host plant immunity. PLoS Pathog. 7:e1002348. Published online.

Galan, J. E., and Collmer, A. 1999. Type III secretion machines: Bacterial devices for protein delivery into host cells. Science 284:1322-1328.

Gopalan, S., Wei, W., and He, S. Y. 1996. hrp gene-dependent induction of hin1: A plant gene activated rapidly by both harpins and the avrPto gene-mediated signal. Plant J. 10:591-600

Gueneron, M., Timmers, A. C., Boucher, C., and Arlat, M. 2000. Two novel proteins, PopB, which has functional nuclear localization signals, and $\mathrm{PopC}$, which has a large leucine-rich repeat domain, are secreted through the hrp-secretion apparatus of Ralstonia solanacearum. Mol. Microbiol. 36:261-277.

Guidot, A., Prior, P., Schoenfeld, J., Carrere, S., Genin, S., and Boucher, C. 2007. Genomic structure and phylogeny of the plant pathogen Ralstonia solanacearum inferred from gene distribution analysis. J. Bacteriol. 189:377-387

Guidot, A., Coupat, B., Fall, S., Prior, P., and Bertolla, F. 2009. Horizontal gene transfer between Ralstonia solanacearum strains detected by comparative genomic hybridization on microarrays. ISME J 3:549-562.

Ham, J. H., Melanson, R. A., and Rush, M. C. 2010. Burkholderia glumae: Next major pathogen of rice? Mol. Plant Pathol. 12:329-339.

Hann, D. R., Gimenez-Ibanez, S., and Rathjen, J. P. 2010. Bacterial virulence effectors and their activities. Curr. Opin. Plant Biol. 13:388-393.

Hayward, A. C. 2000. Ralstonia solanacearum. Pages 32-42 in: Encyclopedia of Microbiology. J. Lederberg, ed. Academic Press, Dordrecht, The Netherlands.

He, S. Y., Nomura, K., and Whittam, T. S. 2004. Type III protein secretion mechanism in mammalian and plant pathogens. Biochim. Biophys. Acta 1694:181-206.

Hogenhout, S. A., Van der Hoorn, R. A., Terauchi, R., and Kamoun, S. 2009. Emerging concepts in effector biology of plant-associated organisms. Mol. Plant-Microbe Interact. 22:115-122.

Hong, J., Ji, P., Momol, M. T., Jones, J. B., Olson, S. M., Pradhanang, P., and Guven, K. 2005. Ralstonia solanacearum detection in tomato irrigation ponds and weeds. Pages 309-311 in: Proceedings of the First International Symposium on Tomato Diseases. International Society for Horticultural Science, Orlando, FL, U.S.A.

Hu, J., Barlet, X., Deslandes, L., Hirsch, J., Feng, D. X., Somssich, I., and Marco, Y. 2008. Transcriptional responses of Arabidopsis thaliana during wilt disease caused by the soil-borne phytopathogenic bacterium, Ralstonia solanacearum. PLoS ONE 3:e2589. Published online.

Huelsenbeck, J. P., and Ronquist, F. 2001. MRBAYES: Bayesian inference of phylogenetic trees. Bioinformatics 17:754-755.

Jones, J. D., and Dangl, J. L. 2006. The plant immune system. Nature 444:323-329.

Katoh, K., Misawa, K., Kuma, K., and Miyata, T. 2002. MAFFT: A novel method for rapid multiple sequence alignment based on fast Fourier transform. Nucleic Acids Res. 30:3059-3066.

Kay, S., and Bonas, U. 2009. How Xanthomonas type III effectors manipulate the host plant. Curr. Opin. Microbiol. 12:37-43.

Keogh, R. C., Deverall, B. J., and McLeod, S. 1980. Comparison of histological and physiological responses to Phakopsora pachyrhizi in resistant and susceptible soybean. Trans. Br. Mycol. Soc. 74:329-333.

Kiba, A., Tomiyama, H., Takahashi, H., Hamada, H., Ohnishi, K., Okuno, T., and Hikichi, Y. 2003. Induction of resistance and expression of defense-related genes in tobacco leaves infiltrated with Ralstonia solanacearum. Plant Cell Physiol. 44:287-295.

Kim, N.H., Choi, H.W., and Hwang, B.K. 2010. Xanthomonas campestris pv. vesicatoria effector AvrBsT induces cell death in pepper, but suppresses defense responses in tomato. Mol. Plant-Microbe Interact. 23:1069-1082.

Kvitko, B. H., Park, D. H., Velasquez, A. C., Wei, C. F., Russell, A. B., Martin, G. B., Schneider, D. J., and Collmer, A. 2009. Deletions in the repertoire of Pseudomonas syringae pv. tomato DC3000 type III secretion effector genes reveal functional overlap among effectors. PLoS Pathog. 5:e1000388. Published online.

Lavie, M., Shillington, E., Eguiluz, C., Grimsley, N., and Boucher, C.
2002. PopP1, a new member of the YopJ/AvrRxv family of type III effector proteins, acts as a host-specificity factor and modulates aggressiveness of Ralstonia solanacearum. Mol. Plant-Microbe Interact. 15:1058-1068

Lee, P. C., Stopford, C. M., Svenson, A. G., and Rietsch, A. 2010. Control of effector export by the Pseudomonas aeruginosa type III secretion proteins PcrG and PcrV. Mol. Microbiol. 75:924-941.

Lewis, J. D., Guttman, D. S., and Desveaux, D. 2009. The targeting of plant cellular systems by injected type III effector proteins. Semin. Cell Dev. Biol. 20:1055-1063.

Lewis, J. D., Lee, A., Ma, W., Zhou, H., Guttman, D. S., and Desveaux, D. 2011. The YopJ superfamily in plant-associated bacteria. Mol. Plant Pathol. 12:928-937.

Lin, Y. M., Chou, I. C., Wang, J. F., Ho, F. I., Chu, Y. J., Huang, P. C., Lu, D. K., Shen, H. L., Elbaz, M., Huang, S. M., and Cheng, C. P. 2008. Transposon mutagenesis reveals differential pathogenesis of Ralstonia solanacearum on tomato and Arabidopsis. Mol. Plant-Microbe Interact. 21:1261-1270.

Macho, A. P., Guidot, A., Barberis, P., Beuzon, C. R., and Genin, S. 2010. A competitive index assay identifies several Ralstonia solanacearum type III effector mutant strains with reduced fitness in host plants. Mol. Plant-Microbe Interact. 23:1197-1205.

Marlovits, T., and Stebbins, C. 2009. Type III secretion systems shape up as they ship out. Curr. Opin. Microbiol. 13:1-6.

Marx, C. J., and Lidstrom, M. E. 2002. Broad-host-range cre-lox system for antibiotic marker recycling in gram-negative bacteria. Biotechniques 33:1062-1067.

Milling, A., Babujee, L., and Allen, C. 2011. Ralstonia solanacearum extracellular polysaccharide is a specific elicitor of defense responses in wilt-resistant tomato plants. PLoS One 6:e15853. Published online.

Mole, B. M., Baltrus, D. A., Dangl, J. L., and Grant, S. R. 2007. Global virulence regulation networks in phytopathogenic bacteria. Trends Microbiol. 15:363-371.

Monteiro, F., Sole, M., van Dijk, I., and Valls, M. 2012. A chromosomal insertion toolbox for promoter probing, mutant complementation and pathogenicity studies in Ralstonia solanacearum. Mol. Plant-Microbe Interact. 25: 557-568.

Mukaihara, T., and Tamura, N. 2009. Identification of novel Ralstonia solanacearum type III effector proteins through translocation analysis of $h r p B$-regulated gene products. Microbiology 155:2235-2244.

Mukaihara, T., Tamura, N., and Iwabuchi, M. 2010. Genome-wide identification of a large repertoire of Ralstonia solanacearum type III effector proteins by a new functional screen. Mol. Plant-Microbe Interact. 23:251-262.

Naum, M., Brown, E. W., and Mason-Gamer, R. J. 2009. Phylogenetic evidence for extensive horizontal gene transfer of type III secretion system genes among enterobacterial plant pathogens. Microbiology 155:31873199.

Pontier, D., Tronchet, M., Rogowsky, P., Lam, E., and Roby, D. 1998. Activation of hsr203, a plant gene expressed during incompatible plantpathogen interactions, is correlated with programmed cell death. Mol. Plant-Microbe Interact. 11:544-554

Poueymiro, M., and Genin, S. 2009. Secreted proteins from Ralstonia solanacearum: A hundred tricks to kill a plant. Curr. Opin. Microbiol. 12:44-52.

Poueymiro, M., Cunnac, S., Barberis, P., Deslandes, L., Peeters, N., Cazale-Noel, A.C., Boucher, C., and Genin, S. 2009. Two type III secretion system effectors from Ralstonia solanacearum GMI1000 determine host-range specificity on tobacco. Mol. Plant-Microbe Interact. 22:538-550.

Preston, G. M. 2007. Metropolitan microbes: Type III secretion in multihost symbionts. Cell Host Microbe 2:291-294.

Rahme, L. G., Tan, M. W., Le, L., Wong, S. M., Tompkins, R. G., Calderwood, S. B., and Ausubel, F. M. 1997. Use of model plant hosts to identify Pseudomonas aeruginosa virulence factors. Proc. Natl. Acad. Sci. U.S.A. 94:13245-13250.

Rainbow, L., Hart, C. A., and Winstanley, C. 2002. Distribution of type III secretion gene clusters in Burkholderia pseudomallei, B. thailandensis and B. mallei. J. Med. Microbiol. 51:374-384.

Remigi, P., Anisimova, M., Guidot, A., Genin, S., and Peeters, N. 2011. Functional diversification of the GALA type III effector family contributes to Ralstonia solanacearum adaptation on different plant hosts New Phytol. 192:976-987.

Robertson, A. E., Wechter, W. P., Denny, T. P., Fortnum, B. A., and Kluepfel, D. A. 2004. Relationship between avirulence gene (avrA) diversity in Ralstonia solanacearum and bacterial wilt incidence. Mol. Plant-Microbe Interact. 17:1376-1384.

Salanoubat, M., Genin, S., Artiguenave, F., Gouzy, J., Mangenot, S., Arlat, M., Billault, A., Brottier, P., Camus, J. C., Cattolico, L., Chandler, M., Choisne, N., Claudel-Renard, C., Cunnac, S., Demange, N., Gaspin, C., 
Lavie, M., Moisan, A., Robert, C., Saurin, W., Schiex, T., Siguier, P. Thebault, P., Whalen, M., Wincker, P., Levy, M., Weissenbach, J., and Boucher, C. A. 2002. Genome sequence of the plant pathogen Ralstonia solanacearum. Nature 415:497-502.

Sambrook, J., and Russell, D. 2001. Molecular Cloning: A Laboratory Manual, 3rd ed. Cold Spring Harbor Laboratory Press, Cold Spring Harbor, NY, U.S.A.

Schulze-Lefert, P., and Panstruga, R. 2010. A molecular evolutionary concept connecting nonhost resistance, pathogen host range, and pathogen speciation. Trends Plant Sci. 16:117-125.

Segonzac, C., and Zipfel, C. 2011. Activation of plant pattern-recognition receptors by bacteria. Curr. Opin. Microbiol. 14:54-61.

Shan, L., He, P., and Sheen, J. 2007. Intercepting host MAPK signaling cascades by bacterial type III effectors. Cell Host Microbe 1:167-174.

Smith, J. J., Jones, D. R., Karamura, E. B., Blomme, G., and Turyagyenda, F. L. 2008. An analysis of the risk from Xanthomonas campestris pv. musacearum to banana cultivation in Eastern, Central and Southern Africa, Montpellier, France.

Sohn, K. H., Lei, R., Nemri, A., and Jones, J. D. 2007. The downy mildew effector proteins ATR1 and ATR13 promote disease susceptibility in Arabidopsis thaliana. Plant Cell 19:4077-4090.

Song, C., and Yang, B. 2010. Mutagenesis of 18 type III effectors reveals virulence function of XopZ(PXO99) in Xanthomonas oryzae pv. oryzae. Mol. Plant-Microbe Interact. 23:893-902.

Stavrinides, J., McCann, H. C., and Guttman, D. S. 2008. Host-pathogen interplay and the evolution of bacterial effectors. Cell Microbiol. 10:285292.

Tao, Y., Xie, Z., Chen, W., Glazebrook, J., Chang, H.-S., Han, B., Zhu, T., Zou, G., and Katagiri, F. 2003. Quantitative Nature of Arabidopsis Responses during Compatible and Incompatible Interactions with the Bacterial Pathogen Pseudomonas syringae. Plant Cell Online 15:317-330.

Tasset, C., Bernoux, M., Jauneau, A., Pouzet, C., Briere, C., KiefferJacquinod, S., Rivas, S., Marco, Y., and Deslandes, L. 2010. Autoacetylation of the Ralstonia solanacearum effector PopP2 targets a lysine residue essential for RRS1-R-mediated immunity in Arabidopsis. PLoS Pathog. 6:e1001202. Published online.

Tayeb, L. A., Lefevre, M., Passet, V., Diancourt, L., Brisse, S., and Grimont, P. A. D. 2008. Comparative phylogenies of Burkholderia, Ralstonia, Comamonas, Brevundimonas and related organisms derived from rpoB, gyrB and rrs gene sequences. Res. Microbiol. 159:169-177.

Thordal-Christensen, H., Zhang, Z., Wei, Y., and Collinge, D. B. 1997. Subcellular localization of $\mathrm{H}_{2} \mathrm{O}_{2}$ in plants. $\mathrm{H}_{2} \mathrm{O}_{2}$ accumulation in papillae and hypersensitive response during the barley-powdery mildew interaction. Plant J. 11:1187-1194.

Torres, M. A. 2010. ROS in biotic interactions. Physiol. Plant. 138:414429.
Tsuda, K., and Katagiri, F. 2010. Comparing signaling mechanisms engaged in pattern-triggered and effector-triggered immunity. Curr. Opin. Plant Biol. 13:459-465.

Turner, M., Jauneau, A., Genin, S., Tavella, M. J., Vailleau, F., Gentzbittel, L., and Jardinaud, M. F. 2009. Dissection of bacterial wilt on Medicago truncatula revealed two type III secretion system effectors acting on root infection process and disease development. Plant Physiol. 150:1713-1722.

Viallard, V., Poirier, I., Cournoyer, B., Haurat, J., Wiebkin, S., OphelKeller, K., and Balandreau, J. 1998. Burkholderia graminis sp. nov., a rhizospheric Burkholderia species, and reassessment of Pseudomonas phenazinium, Pseudomonas pyrrocinia and Pseudomonas glathei as Burkholderia. Int. J. Syst. Bacteriol. 48:549-563.

Wang, J.-F., Olivier, J., Thoquet, P., Mangin, B., Sauviac, L., and Grimsley, N. H. 2000. Resistance of tomato line Hawaii7996 to Ralstonia solanacearum Pss4 in Taiwan is controlled mainly by a major strain-specific locus. Mol. Plant-Microbe Interact. 13:6-13.

Willems, A., Goor, M., Thielemans, S., Gillis, M., Kersters, K., and De Ley, J. 1992. Transfer of several phytopathogenic Pseudomonas species to Acidovorax as Acidovorax avenae subsp. avenae subsp. nov., comb. nov., Acidovorax avenae subsp. citrulli, Acidovorax avenae subsp. cattleyae, and Acidovorax konjaci. Int. J. Syst. Bacteriol. 42:107-119.

Wroblewski, T., Caldwell, K. S., Piskurewicz, U., Cavanaugh, K. A., Xu, H., Kozik, A., Ochoa, O., McHale, L. K., Lahre, K., Jelenska, J., Castillo, J. A., Blumenthal, D., Vinatzer, B. A., Greenberg, J. T., and Michelmore, R. W. 2009. Comparative large-scale analysis of interactions between several crop species and the effector repertoires from multiple pathovars of Pseudomonas and Ralstonia. Plant Physiol. 150:1733-1749.

Wu, M., and Eisen, J.A. 2008. A simple, fast, and accurate method of phylogenomic inference. Genome Biol. 9:R151.

Wuthiekanun, V., and Peacock, S. J. 2006. Management of melioidosis. Expert Rev. Anti-Infe. 4:445-455.

Zhou, J. M., and Chai, J. 2008. Plant pathogenic bacterial type III effectors subdue host responses. Curr. Opin. Microbiol. 11:179-185.

\section{AUTHOR-RECOMMENDED INTERNET RESOURCES}

National Center for Biotechnology Information BLAST database: blast.ncbi.nlm.nih.gov/Blast.cgi

European Bioinformatics Institute (EBI) InterPro server: www.ebi.ac.uk/Tools/pfa/iprscan

EBI EMBOSS needle server: www.ebi.ac.uk/Tools/psa/emboss_needle GBlocks server: molevol.cmima.csic.es/castresana/Gblocks_server.html MAFFT server: mafft.cbrc.jp/alignment/server

PhyM server: www.atgc-montpellier.fr/phym

PHYRE database: www.sbg.bio.ic.ac.uk/ phyre 